10.1016/j.ress.2018.11.029

\title{
Literature Review on Modeling and Simulation of Energy Infrastructures from a Resilience Perspective
}

\author{
Jing Wang ${ }^{\mathrm{a}}$, Wangda Zuo ${ }^{\mathrm{a}, *}$, Landolf Rhode-Barbarigos ${ }^{\mathrm{b}}$, Xing Lu ${ }^{\mathrm{a}}$, Jianhui Wang ${ }^{\mathrm{c}}$, Yanling Lin ${ }^{\mathrm{d}}$ \\ ${ }^{a}$ Department of Civil, Environmental and Architectural Engineering, University of Colorado Boulder, \\ Boulder, CO, USA \\ ${ }^{\mathrm{b}}$ Department of Civil, Architectural, and Environmental Engineering, University of Miami, Miami, FL, \\ USA \\ ${ }^{\mathrm{c}}$ Department of Electrical Engineering, Southern Methodist University, Dallas, TX, USA \\ ${ }^{\mathrm{d}}$ School of Electrical Engineering, Xi'an Jiaotong University, Xi'an, China
}

\section{Abstract}

Recent years have witnessed an increasing frequency of disasters, both natural and human-induced. This applies pressure to critical infrastructures (CIs). Among all the CI sectors, the energy infrastructure plays a critical role, as almost all other CIs depend on it. In this paper, 30 energy infrastructure models dedicated for the modeling and simulation of power or natural gas networks are collected and reviewed using the emerging concept of resilience. Based on the review, typical modeling approaches for energy infrastructure resilience problems are summarized and compared. The authors, then, propose five indicators for evaluating a resilience model; namely, catering to different stakeholders, intervening in development phases, dedicating to certain stressor and failure, taking into account different interdependencies, and involving socio-economic characteristics. As a supplement, other modeling features such as data needs and time scale are further discussed. Finally, the paper offers observations of existing energy infrastructure models as well as future trends for energy infrastructure modeling.

Keywords: energy infrastructure, resilience, power grid, modeling and simulation, model evaluation, natural gas network

\section{Introduction}

\subsection{Critical Infrastructure (CI) Protection}

A nation's health, wealth, and security rely on the production and distribution of goods and services. The array of physical assets, processes and organizations through which these goods and services move are called infrastructures (Moteff 2010). Among all infrastructure systems, the critical infrastructures (CIs) are those systems "whose incapacity or destruction would have a

\footnotetext{
* Corresponding author: Prof. Wangda Zuo, ECCE 247, UCB 428, Boulder, CO 80309-0428. Tel.: +1 303-492-4333;
}

E-mail:wangda.zuo@colorado.edu. 
debilitating impact on the defense and economic security" (PCCIP 1997). Presidential Policy Directives 21 Critical Infrastructure Security and Resilience (PPD-21) identified 16 critical sectors of infrastructures including: chemical, commercial facilities, communication, critical manufacturing, dams, defense industrial base, emergency services, energy, financial services, food and agriculture, government facilities, healthcare and public health, information technology, nuclear reactors, materials, and waste, transportation systems, and water and wastewater systems.

However, human-induced and natural disasters, such as the 9/11 terrorist attacks (History.com 2017) in 2001 and Hurricane Katrina (History.com 2018) in 2005, further highlighted the vulnerability of CI systems and raised the awareness about their protection. In the United States, the National Infrastructure Simulation and Analysis Center (NISAC) and the Department of Homeland Security established in 2001 and 2002, respectively, aim at improving CI protection. PPD-8 and PPD-21 specifically addressed the national preparedness of CI systems.

Similar organizations and programs have also been developed in other regions and countries, such as the European Program on Critical Infrastructure Protection, the Critical Infrastructure Protection Implementation Plan in Germany and the Critical Infrastructure Resilience Program in the UK (Ouyang 2014). In Asia, recovering from the earthquake and tsunami at Tokushima, the National Resilience Program of Japan dedicated \$210 billion worth investment in 2013 to increase the overall resilience of energy, water, transportation and other CIs (Dewit 2016). Being aware that the majority of outages have roots in the distribution system, the Chinese National Energy Administration allocated 20 trillion CNY for the distribution renovation during 2015-2020 to increase reliability, power quality, and resilience to disruptions. The modeling and simulation of CIs for protection and resilience purposes have thus received significant interests among universities, national laboratories and private companies.

\subsection{The Concept of Resilience}

Resilience, as an emerging concept in the area of engineering, was first introduced in 1973 by Holling into the fields of ecology and evolution (Holling 1973). This concept was first used to describe the ability of an ecosystem to continue functioning after changes. Nowadays, resilience has been broadly applied across many fields, including natural disaster and risk management (Cutter et al. 2014), civil infrastructure studies (Bocchini and Frangopol 2012; Bocchini et al. 2013; Frangopol and Bocchini 2011), system engineering (Dessavre et al. 2016), energy systems (Bie et al. 2017; Watson et al. 2014), etc.

Though consensus on resilience definition is lacking (Hosseini et al. 2016), the essence of resilience definitions is generally the same, that is, it is an overarching concept that encompasses the system performance before and after disastrous events. Francis and Bekera (2014) reviewed various approaches to defining and assessing resilience and identified three resilience capacities: adaptive capacity, absorptive capacity, and recoverability. Resilience therefore can be defined as "the ability of an entity to anticipate, resist, absorb, respond to, adapt to and recover from a disturbance" (Carlson et al. 2012).

Resilience is a multi-dimensional concept. Its qualitative and quantitative studies often involve interdisciplinary efforts. Meerow et al. (2016) reviewed the literature on urban resilience and concluded that "applying resilience in different contexts requires answering: Resilience for whom 
and to what? When? Where? And Why?" They, thus, pointed out the key considerations in the application of resilience: the stakeholder, the stressor, the temporal and spatial scale, and the motivation. Shaw and IEDM Team (2009) developed a Climate Disaster Resilience Index to measure the existing level of climate disaster resilience of targeted areas. This index utilizes 25 variables in five resilience-based dimensions: natural, physical, social, economic and institutional. Carlson et al. (2012) and McManus et al. (2007) provided frameworks for system-level and regionlevel resilience overview to address personal, business, governmental, and infrastructure aspects of resilience. Roege et al. (2014) formulated a scoring matrix to evaluate the system's capability to plan, absorb, recover and adapt from the perspective of physical, information, cognitive and social.

In this work, reviewing energy infrastructure models from a resilience perspective implies utilizing different resilience-based dimensions and considerations during the evaluation of the selected models. Consequently, the models' ability to promote resilience in energy infrastructures against short-term disruptions and long-term degradations is addressed, not only from a physical perspective, but also socio-economically. \\ 1.3 Energy Infrastructure Resilience}

Energy infrastructures include electric power, natural gas, and fuel networks. Among all the CI sectors, energy infrastructure might be identified as the most crucial one due to the enabling functions they provide across all other CI sectors (PPD-21). For example, water supply and sewer systems rely on electric power systems to operate their pump stations. Information and telecommunication systems rely on power networks to carry out information transmission tasks. Transportation systems rely on fuel networks to obtain power for all kinds of vehicles. The dependence of other critical infrastructures on the energy network can lead to its vulnerability: Disruptions in the energy system may transverse to other dependent infrastructure systems and possibly even back to itself, where the failure originated (Huang et al. 2014; Buldyrev et al. 2010). This cascading and escalating characteristic of failure adds to energy network's vulnerability. Energy infrastructures are also vulnerable to climate change. For example, the rising sea level and increasing frequency of major storms lead to severe floods in coastal areas, where a lot of energy infrastructures are located (Bollinger 2011), such as power plants, natural gas facilities, and oil and gas refineries. Moreover, high-impact low-probability events, such as hurricanes and terrorist attacks, further threaten the operation of energy infrastructures.

Based on the above-mentioned importance and vulnerability, the study of energy infrastructure resilience has become an urgent and significant research topic. Different researchers approach this problem in various ways. Many scholars simulate energy infrastructure resilience as an optimal operation problem (Arif et al. 2018; Chen et al. 2016; Ding et al. 2017; Chen et al. 2018; Manshadi and Khodayar 2015; Yuan et al. 2016). Some adopt agent-based modeling (ABM) technique to reveal the complex interactions among energy system components (Dudenhoeffer et al. 2006; Pederson et al. 2006; Li et al. 2016; Keirstead et al. 2010). Others improve traditional topological metrics of power grids by embodying its physical behavior (Bompard et al. 2009). Also, in response to the emergence of "big data" resources, some researches apply large-scale data analysis in the energy resilience studies, especially for power grid studies (Ji et al. 2016; Peter et al. 2015).

42 Although some researches consider resilience and reliability of energy infrastructures in the same 43 topic (Albasrawi et al. 2014; Amin 2008), it is to note that resilience and reliability are not the 
same. While reliability is the ultimate goal that system designers and providers strive for, resilience is the way to achieve it by recovering fast from and adapting to disruptions (Clark-Ginsberg 2016). The focus of this review paper is the modeling and simulation of energy infrastructure resilience.

\subsection{Work Scope and Highlights}

The modeling and simulation of CIs has been the topic of a few critical reviews. Eusgeld et al. (2008) reviewed eight modeling and simulation techniques for interdependent CIs; namely, agentbased modeling, system dynamics, hybrid system modeling, input-output-model, hierarchical holographic modeling, critical path method, high level architecture and petri nets. They also proposed seven model evaluation criteria concerning modeling focus, methodical design strategies, type of interdependencies, types of events for simulation, event consequences, data needs and monitoring field. More recently, Ouyang (2014) reviewed existing approaches for CI modeling and simulation grouping them into six types: empirical approaches, agent-based approaches, system dynamics based approaches, economic theory based approaches, network based approaches, and others. Existing studies were categorized and reviewed in terms of fundamental principles. Different approaches were further compared concerning the inclusion of sampled resilience improvement strategies.

However, both aforementioned studies had a working scope of general CI systems rather than focusing on energy infrastructures. The work of Eusgeld et al. (2008) only compared different modeling approaches against each other without reviewing the details of specific models. The work of Ouyang (2014) adopted several resilience improvement strategies to evaluate the modeling approaches but did not address other important issues of resilience such as the stakeholder or the temporal scale.

In this paper, we conduct a comprehensive review of 30 energy infrastructure models collected from open literature. In the overview part, we first summarize the modeling scenarios and the problems tackled by the models, as well as their typical assumptions. Based on the literature review, typical approaches to study energy infrastructure resilience are introduced with exemplary models. As the next step, we propose five selected resilience indicators; namely, catering to different stakeholders, intervening in development phases, dedicating to certain stressor and failure, taking into account different interdependencies and involving socio-economic characteristics. Other features are further discussed such as model type, data needs, etc. This review highlights the features and trends of existing models concerning their ability to address the multi-dimensional aspects of energy infrastructure resilience while stressing the characteristics of different modeling approaches. From reading the paper, the readers could gain knowledge of: 1) what are the differences among major energy infrastructure models, 2) what are the modeling needs from a resilience perspective through the proposed resilience indicators, 3) what kind of energy infrastructure model is needed in the future to better equip energy infrastructure resilience studies.

The remainder of the paper is organized as follows: Section 2 introduces the model-collection procedure, provides an overview of the models and summarizes typical modeling approaches. Sections 3 proposes the resilience indicators, as well as other selected modeling features. Section 4 gives a discussion based on the proposed indicators and modeling features. Finally, concluding remarks and future trends in the field are stated in Section 5. 


\section{$1 \quad 2$ Reviewing Existing Energy Infrastructure Models}

\section{$2 \quad 2.1 \quad$ Collection of Models}

3 The review focus of this paper are models aiming at energy infrastructure operation, protection, or resilience enhancement. Three model collection methods have been applied: 1) searching literature with a variety of keywords, 2) checking the references and citations of the papers identified through method 1,3) referring to the publications of selected research groups in the field.

The keywords used in the literature search are listed in Table 1. The search strings accounted for the fact that different literature may use different terms for the same object (i.e. protection and security). As a result, 210 journal and conference papers from reliability, infrastructure and energy related journals were initially collected. Related papers citing or cited by the papers found in the first stage were reviewed as well.

Table 1 Keywords for Literature Search

\begin{tabular}{|c|c|c|c|c|}
\hline & \multirow{7}{*}{+} & \multirow{3}{*}{ Infrastructure } & & Model* \\
\hline Energy & & & & Simulat* \\
\hline Power & & & & Resilien* \\
\hline Electric* & & & + & Vulnerab* \\
\hline Gas & & & & Protect* \\
\hline \multirow{2}{*}{ Fuel } & & & & Secur* \\
\hline & & & & Risk \\
\hline
\end{tabular}

Models were also collected by reviewing the work done by active research groups in CI modeling and simulation field such as NISAC, ANL, Los Alamos National Laboratory (LANL), etc. NISAC experts use advanced modeling and simulation capabilities to address CI interdependencies, vulnerabilities, and complexities in the U.S. Scientists at ANL use the ABM technique to study various aspects of energy network resilience. They also developed models for the natural gas and petroleum fuel networks (Pederson et al. 2006). The Interdependent Energy Infrastructure Simulation System (Toole and McCown 2008) developed by LANL is an actor-based model that helps decision-makers understand and assess intrinsic vulnerabilities in CIs.

Through the above-mentioned procedure, this study identified 30 models for energy infrastructures. In the selected models, 17 are applied on power networks, 3 on natural gas networks, 4 on both power and natural gas networks, and the remaining 6 are applied on other energy infrastructure systems. When looking at the detailed scenarios of the models, most models for power networks focus on power transmission networks. Nonetheless, the research on distribution systems is emerging. Some of the models integrate financial networks, human activity, or supervisory control and data acquisition (SCADA). The natural gas network models mainly focus on the analysis and restoration of natural gas transmission pipelines. The models for both power and natural gas networks are dedicated to studying the interdependencies between the two systems. Other models include energy generation and storage system model (Page et al. 2013), coal distribution network 
model (Shih et al. 2009), crude oil and petroleum product transport pipeline model (Pederson et al. 2006), and integrated urban energy systems model (Keirstead et al. 2010).

\subsection{Model Overview}

To understand what problems the research community of energy infrastructure resilience is trying to tackle and how the researchers are approaching these problems, this section first summarizes the research problems of the selected models and their corresponding key assumptions. Then, in the following section, the modeling approaches adopted by these models are introduced, representing typical methods for conducting energy infrastructure resilience studies.

Given that resilience describes a system's ability to sustain disruptions and to recover quickly from them, energy infrastructure resilience models concentrate on solving two major problems: 1) resource allocation and hardening planning in the preparation stage, 2) power outage management and service restoration in the immediate aftermath and recovery stage. Due to the limitation of budgets, how to identify the most vulnerable components in the system, harden them with minimized economic costs and gain the most effects out of the hardening measures is one main topic the research community cares about. The second topic aims to mitigate the impacts of the disasters and to recover the services quickly. Typical implementations include models that simulate the restoration process or that abstract the restoration process as an optimal control problem (Arif et al. 2018). Common restoration measures include repair crew dispatch, distributed generation (DG), switch device remote control, etc.

Since the energy infrastructure sector is closely related to other CI sectors, an emerging number of researches focus on the study of interdependencies within the energy infrastructure sector and across CI sectors. Within the energy infrastructure sector, the interaction between the natural gas system and the power grid system is studied (Erdener et al. 2014). Across different sectors, researchers try to involve energy, water, transportation and communication systems into the same modeling and simulation framework and find resilient solutions on a more holistic scale.

For different application focuses, the models are usually developed under various assumptions of the real world. In models of distributed generation or microgrid technologies, it is typically assumed that the remotely controlled automatic switch devices are available in the distribution network so that lines can be opened/closed and loads can be connected/disconnected to form multiple microgrids. The switches are assumed to have local communication capabilities to exchange information with its neighboring switches (Chen et al. 2016). In most resilience models that simulate the defender and attacker activities, the decision maker has a budget to harden a maximum of power lines and to place a maximum of DG units and the system operators are aware of the status of all the components after the occurrence of the outage (Yuan et al. 2016). The worstcase attack scenario occurs and the hardened lines and nodes are assumed to be able to survive the disasters. For models that study the weather impact, it is usually assumed the system is exposed to the same weather conditions at any given time by modeling the weather event as a standstill event, which reduces the complexity of the modeling procedure because no regional weather aspects are considered. The restoration time during high and extreme wind speed events is equal to the restoration time during normal wind speeds (Panteli and Mancarella 2017; Cadini et al. 2017). For models studying interdependencies between power and gas systems, it is usually assumed that electricity generation consumes gas and gas compressors consumes electricity (Yuan et al. 2016). Other specific assumptions depend on the modeling objectives and the scale of the model. 
1 Table 2 summarizes basic information for the selected models including name, developer/author, 2 scenario, and purpose/problem tackled. "Scenario" gives the specific modeling object of a model. 3 "Purpose/problem tackled" describes the targeted problem the model was developed to solve. 4 Among all the models, $15 \%$ are for power outage management and service restoration, $21 \%$ are 5 for vulnerability and reliability analysis, $18 \%$ are for resource allocation and hardening planning, $612 \%$ are for infrastructure interdependency analysis. The rest address problems such as electricity 7 market studies, weather event impact studies, general presentation and analysis, etc.

Table 2 Basic Information of the Selected Models

\begin{tabular}{|c|c|c|c|c|}
\hline & Name & Developer/Author & Scenario & Purpose/ Problem Tackled \\
\hline 1 & $\begin{array}{l}\text { Two-stage outage } \\
\text { management model } \\
(2018)\end{array}$ & Arif et al. & Power distribution systems & $\begin{array}{l}\text { Improve the computational efficiency in solving } \\
\text { outage management problems for large distribution } \\
\text { systems, co-optimize the repair, reconfiguration, } \\
\text { and DG dispatch to maximize the picked-up loads } \\
\text { and minimize the repair time. }\end{array}$ \\
\hline 2 & $\begin{array}{l}\text { Microgrids formation } \\
\text { scheme (2016) }\end{array}$ & Chen et al. & Power distribution systems & $\begin{array}{l}\text { Create a microgrid operation scheme to restore } \\
\text { critical loads from the power outage by controlling } \\
\text { the ON/OFF status of the remotely controlled } \\
\text { switch devices and DG. }\end{array}$ \\
\hline 3 & $\begin{array}{l}\text { Sequential service } \\
\text { restoration framework } \\
(2018)\end{array}$ & Chen et al. & Power distribution systems & $\begin{array}{l}\text { Generate a sequential service restoration framework } \\
\text { for distribution systems and microgrids in large- } \\
\text { scale power outages. A sequence of control actions } \\
\text { includes coordinating switches, distributed } \\
\text { generators, and switchable loads to form multiple } \\
\text { isolated microgrids. }\end{array}$ \\
\hline 4 & $\begin{array}{l}\text { Multiple energy resilient } \\
\text { operation model (2015) }\end{array}$ & $\begin{array}{l}\text { Manshadi and } \\
\text { Khodayar }\end{array}$ & Electricity and natural gas systems & $\begin{array}{l}\text { Identify the vulnerable components and ensure the } \\
\text { resilient operation of coordinated electricity and } \\
\text { natural gas infrastructures considering multiple } \\
\text { disruptions within the microgrid by improving the } \\
\text { resilience of generation and demand scheduling. }\end{array}$ \\
\hline 5 & $\begin{array}{l}\text { Two-stage robust } \\
\text { optimization model } \\
(2016)\end{array}$ & Yuan et al. & Power distribution systems & $\begin{array}{l}\text { Resilient distribution network planning to } \\
\text { coordinate the hardening distributed generation } \\
\text { resource allocation with the objective of minimizing } \\
\text { the system damage. }\end{array}$ \\
\hline 6 & $\begin{array}{l}\text { A risk optimization model } \\
(2017)\end{array}$ & Nezamoddini et al. & Power transmission networks & $\begin{array}{l}\text { Determine the optimal investment decision for the } \\
\text { resilient design of transmission systems against } \\
\text { physical attacks. The investment costs are } \\
\text { minimized such that the load curtailment does not } \\
\text { exceed a certain threshold value. }\end{array}$ \\
\hline 7 & $\begin{array}{l}\text { The planner-attacker- } \\
\text { defender model (2017) }\end{array}$ & Fang et al. & Power transmission networks & $\begin{array}{l}\text { Study the combination of capacity expansion and } \\
\text { switch installation in electric systems that ensures } \\
\text { optimum performance under nominal operations } \\
\text { and attacks. The planner-attacker-defender model is } \\
\text { adopted to develop decisions that minimize } \\
\text { investment and operating costs, and functionality } \\
\text { loss after attacks. }\end{array}$ \\
\hline 8 & $\begin{array}{l}\text { Attack structural } \\
\text { vulnerability model } \\
(2010)\end{array}$ & Chen et al. & Power transmission networks & $\begin{array}{l}\text { Propose a hybrid approach for structural } \\
\text { vulnerability analysis of power transmission } \\
\text { networks, in which a DC power flow model with } \\
\text { hidden failures is embedded into the traditional } \\
\text { error and attack tolerance methodology. }\end{array}$ \\
\hline 9 & CitInES (2013) & Page et al. & $\begin{array}{l}\text { Energy generation, storage, transport, } \\
\text { distribution systems and demand }\end{array}$ & $\begin{array}{l}\text { Present a multi-energy modelling environment to } \\
\text { simulate and optimize urban energy strategies. } \\
\text { Energy demand is modeled to consider the costs and } \\
\text { impacts of demand-side measures. Optimization } \\
\text { techniques are involved to provide answers to urban } \\
\text { energy infrastructure planning issues. }\end{array}$ \\
\hline
\end{tabular}




\begin{tabular}{|c|c|c|c|c|}
\hline & Name & Developer/Author & Scenario & Purpose/ Problem Tackled \\
\hline 10 & $\begin{array}{l}\text { An improved model for } \\
\text { structural vulnerability } \\
\text { analysis (2009) }\end{array}$ & Chen et al. & Electric power systems & $\begin{array}{l}\text { Structural vulnerability analysis of power networks. } \\
\text { Depicting a typical power network as a weighted } \\
\text { graph based on electrical topology by introducing } \\
\text { its bus admittance matrix. }\end{array}$ \\
\hline 11 & Graph Model (2006) & Holmgren & Electric power systems & $\begin{array}{l}\text { Model electric power delivery networks as graphs, } \\
\text { calculate values of topological characteristics of the } \\
\text { networks, and evaluate different strategies to } \\
\text { decrease the vulnerability of the system. }\end{array}$ \\
\hline 12 & $\begin{array}{l}\text { Tri-level defender- } \\
\text { attacker-defender model } \\
(2018)\end{array}$ & Lin and Bie & Power distribution systems & $\begin{array}{l}\text { Find the best hardening plan under malicious } \\
\text { attacks given the available defending resources and } \\
\text { operational restoration measures for a distribution } \\
\text { system. Resilient operational measures include } \\
\text { optimal DG islanding formation and topology } \\
\text { reconfiguration. }\end{array}$ \\
\hline 13 & $\begin{array}{l}\text { A "proof-of-concept" } \\
\text { model (2011) }\end{array}$ & TU Delft & $\begin{array}{l}\text { The } 380 \mathrm{kV} \text { power network in the } \\
\text { Netherlands }\end{array}$ & $\begin{array}{l}\text { Explore the adaptation of energy infrastructures to } \\
\text { climate change. }\end{array}$ \\
\hline 14 & $\begin{array}{l}\text { Electricity Market } \\
\text { Complex Adaptive } \\
\text { System (2006) }\end{array}$ & ANL & Electric power and financial networks & $\begin{array}{l}\text { Modeling and simulation of operations in } \\
\text { restructured electricity markets. }\end{array}$ \\
\hline 15 & $\begin{array}{l}\text { Natural Gas Infrastructure } \\
\text { Toolset (2006) }\end{array}$ & $\begin{array}{l}\text { ANL, Infrastructure } \\
\text { Assurance Center }\end{array}$ & Natural gas networks & $\begin{array}{l}\text { Provide an analyst with a quick method to access, } \\
\text { review, and display components of the natural gas } \\
\text { network; perform varying levels of component and } \\
\text { systems analysis, and display analysis results. }\end{array}$ \\
\hline 16 & $\begin{array}{l}\text { Critical Infrastructure } \\
\text { Modeling System (2006) }\end{array}$ & INL & $\begin{array}{l}\text { Electric power system, human activity } \\
\text { and SCADA }\end{array}$ & $\begin{array}{l}\text { Provide decision makers with a highly adaptable } \\
\text { and easily constructed 'wargaming' tool to assess } \\
\text { infrastructure vulnerabilities including policy and } \\
\text { response plans. }\end{array}$ \\
\hline 17 & $\begin{array}{l}\text { Critical Infrastructure } \\
\text { Simulation by } \\
\text { Interdependent Agents } \\
(2006)\end{array}$ & University Roma Tre & Electric power system and SCADA & $\begin{array}{l}\text { Analyze short term effects of failures in terms of } \\
\text { fault propagation and performance degradation. }\end{array}$ \\
\hline 18 & $\begin{array}{l}\text { Integrated energy system } \\
\text { reliability evaluation } \\
\text { model (2016) }\end{array}$ & Li et al. & $\begin{array}{l}\text { Electricity distribution network, } \\
\text { distributed renewable energy system, } \\
\text { gas system, cooling, and heating } \\
\text { systems }\end{array}$ & $\begin{array}{l}\text { Present a new reliability evaluation approach, in } \\
\text { which Smart Agent Communication is based system } \\
\text { reconfiguration is integrated into the reliability } \\
\text { evaluation process. }\end{array}$ \\
\hline 19 & SynCity (2010) & $\begin{array}{l}\text { Imperial College } \\
\text { London }\end{array}$ & Urban energy systems & $\begin{array}{l}\text { Provide an integrated, spatially and temporally } \\
\text { diverse representation of urban energy use within a } \\
\text { generalized framework across all the design steps } \\
\text { and in a variety of problem environments. }\end{array}$ \\
\hline 20 & $\begin{array}{l}\text { Resilience evaluation } \\
\text { model (2017) }\end{array}$ & Panteli and Pierluigi & Electric power systems & $\begin{array}{l}\text { Provide a conceptual framework for gaining insight } \\
\text { into the resilience of power systems with focus on } \\
\text { the impact of severe weather events. The effect of } \\
\text { weather is quantified with a stochastic approach. } \\
\text { The resilience of the critical power infrastructure is } \\
\text { modeled and assessed within a context of system- } \\
\text { of-systems that also include human response as a } \\
\text { key dimension. }\end{array}$ \\
\hline 21 & $\begin{array}{l}\text { Multi-microgrid reliability } \\
\text { assessment framework } \\
(2017)\end{array}$ & Farzin et al. & Multi-microgrid distribution system & $\begin{array}{l}\text { Develop a general framework for reliability } \\
\text { assessment of multi-microgrid (MMG) distribution } \\
\text { systems. Investigate reliability impacts of } \\
\text { coordinated outage management strategies in a } \\
\text { MMG distribution network. }\end{array}$ \\
\hline 22 & $\begin{array}{l}\text { Critical Infrastructures } \\
\text { Interdependencies } \\
\text { Integrator (2002) }\end{array}$ & ANL & Natural gas pipelines & $\begin{array}{l}\text { Infrastructure restoration time and/or cost } \\
\text { estimation considering an interdependency analysis. }\end{array}$ \\
\hline
\end{tabular}




\begin{tabular}{|c|c|c|c|c|}
\hline & Name & Developer/Author & Scenario & Purpose/ Problem Tackled \\
\hline 23 & Restore (2011) & ANL & Natural gas pipelines & $\begin{array}{l}\text { Estimate the time and cost of Infrastructure } \\
\text { restoration. }\end{array}$ \\
\hline 24 & $\begin{array}{l}\text { A framework for } \\
\text { reliability/availability } \\
\text { assessment (2017) }\end{array}$ & Cadini et al. & Electric power transmission networks & $\begin{array}{l}\text { Combine an extreme weather stochastic model to a } \\
\text { realistic cascading failure simulator based on a } \\
\text { direct current power flow approximation and a } \\
\text { proportional re-dispatch strategy. Dynamics of the } \\
\text { network is completed by the introduction of a } \\
\text { restoration model accounting for the operating } \\
\text { conditions that a repair crew may encounter during } \\
\text { an extreme weather event. }\end{array}$ \\
\hline 25 & $\begin{array}{l}\text { Interdependent Energy } \\
\text { Infrastructure Simulation } \\
\text { System (2006) }\end{array}$ & LANL & $\begin{array}{l}\text { Electric power and natural gas } \\
\text { infrastructures }\end{array}$ & $\begin{array}{l}\text { Assist individuals in analyzing and understanding } \\
\text { interdependent energy infrastructures. }\end{array}$ \\
\hline 26 & $\begin{array}{l}\text { Framework for Electricity } \\
\text { Production Vulnerability } \\
\text { Assessment (2009) }\end{array}$ & Shih et al. & Coal distribution network & $\begin{array}{l}\text { Use data warehousing and visualization techniques } \\
\text { to explore the interdependencies between coal } \\
\text { mines, rail transportation, and electric power plants. }\end{array}$ \\
\hline 27 & $\begin{array}{l}\text { Critical Infrastructure } \\
\text { Protection Modeling and } \\
\text { Analysis (CIPMA) } \\
\text { Program (2006) }\end{array}$ & $\begin{array}{l}\text { Australian } \\
\text { Government - } \\
\text { Attorney General's } \\
\text { Department }\end{array}$ & CI networks and high priority precincts & $\begin{array}{l}\text { Support business and government decision making } \\
\text { for CI protection, counter-terrorism and emergency } \\
\text { management, especially with regard to prevention, } \\
\text { preparedness, and planning and recovery. }\end{array}$ \\
\hline 28 & $\begin{array}{l}\text { Petroleum Fuels Network } \\
\text { Analysis Model (2006) }\end{array}$ & $\begin{array}{l}\text { ANL, Infrastructure } \\
\text { Assurance Center }\end{array}$ & $\begin{array}{l}\text { Crude oil and petroleum product } \\
\text { transport pipelines }\end{array}$ & $\begin{array}{l}\text { Perform hydraulic calculations of pipeline transport } \\
\text { of crude oil and petroleum products. Introduction of } \\
\text { pipeline component dependencies into critical } \\
\text { infrastructure analyses. }\end{array}$ \\
\hline 29 & $\begin{array}{l}\text { Critical energy } \\
\text { infrastructures (2014) }\end{array}$ & Erdener et al. & Electricity, natural gas and oil systems & $\begin{array}{l}\text { Analysis of the impacts of interdependencies } \\
\text { between electricity and natural gas systems. } \\
\text { Propose an integrated simulation model that reflects } \\
\text { the dynamics of the systems in case of disruptions } \\
\text { and takes the cascading effects of these disruptions } \\
\text { into account. }\end{array}$ \\
\hline 30 & $\begin{array}{l}\text { Fast Analysis } \\
\text { Infrastructure Tool (2006) }\end{array}$ & $\begin{array}{l}\text { Sandia National } \\
\text { Laboratory (SNL) }\end{array}$ & $\begin{array}{l}\text { Electric power, natural gas, and } \\
\text { waterway systems }\end{array}$ & $\begin{array}{l}\text { Determine the significance and interdependencies } \\
\text { associated with elements of the nation's CI. }\end{array}$ \\
\hline
\end{tabular}

\subsection{Modeling Approaches}

3 In this section, we introduce typical modeling approaches for energy infrastructure resilience 4 problems. The models collected in this paper adopt a variety of modeling approaches including 5 optimal operation modeling, topological network modeling, agent-based modeling, probabilistic 6 modeling, system dynamics modeling, empirical modeling, etc.

7 Table 3 lists the modeling approaches and the corresponding models that were collected in this 8 paper.

9 The most common four approaches will be introduced in detail in the following subsections. The 10 rest approaches are introduced briefly in "other approaches". It should be noted that since the 11 review object of this paper is numerical models that could conduct simulations and predict system 12 performance in the real world, no surveys or qualitative studies were included. In the remaining 13 part of this section, each modeling approach is introduced with exemplary models to address their 14 characteristics. 
Table 3 Modeling Approaches for Energy Infrastructure Resilience Problems

\begin{tabular}{|c|c|c|c|}
\hline & \multicolumn{2}{|c|}{ Modeling Approach } & Model Name \\
\hline 1 & \multirow{7}{*}{\multicolumn{2}{|c|}{ Optimal Operation Modeling }} & Two-stage outage management model (Arif et al. 2018) \\
\hline 2 & & & Microgrids formation scheme (Chen et al. 2016) \\
\hline 3 & & & Sequential service restoration framework (Chen et al. 2018) \\
\hline 4 & & & $\begin{array}{l}\text { Multiple energy resilient operation model (Manshadi and Khodayar } \\
\text { 2015) }\end{array}$ \\
\hline 5 & & & Two-stage robust optimization model (Yuan et al. 2016) \\
\hline 6 & & & A risk optimization model (Nezamoddini et al. 2017) \\
\hline 7 & & & The planner-attacker-defender model (Fang and Sansavini 2017) \\
\hline 8 & \multirow{5}{*}{\multicolumn{2}{|c|}{ Topological Network Modeling }} & Attack structural vulnerability model (Chen et al. 2010) \\
\hline 9 & & & CitInES (Page et al. 2013) \\
\hline 10 & & & $\begin{array}{l}\text { An improved model for structural vulnerability analysis (Chen et al. } \\
\text { 2009) }\end{array}$ \\
\hline 11 & & & Graph Model (Holmgren 2006) \\
\hline 12 & & & Tri-level defender-attacker-defender model (Lin and Bie 2018) \\
\hline 13 & \multirow{7}{*}{\multicolumn{2}{|c|}{ Agent-Based Modeling }} & A "proof-of-concept" model (Bollinger 2011) \\
\hline 14 & & & Electricity Market Complex Adaptive System (Pederson et al. 2006) \\
\hline 15 & & & Natural Gas Infrastructure Toolset (Pederson et al. 2006) \\
\hline 16 & & & Critical Infrastructure Modeling System (Dudenhoeffer et al. 2006) \\
\hline 17 & & & $\begin{array}{l}\text { Critical Infrastructure Simulation by Interdependent Agents (Pederson } \\
\text { et al. 2006) }\end{array}$ \\
\hline 18 & & & Integrated energy system reliability evaluation model ( $\mathrm{Li}$ et al. 2016) \\
\hline 19 & & & SynCity (Keirstead et al. 2010) \\
\hline 20 & \multirow{5}{*}{\multicolumn{2}{|c|}{ Probabilistic Modeling }} & Resilience evaluation model (Panteli and Mancarella 2017) \\
\hline 21 & & & Multi-microgrid reliability assessment framework (Farzin et al. 2017) \\
\hline 22 & & & $\begin{array}{l}\text { Critical Infrastructures Interdependencies Integrator (Gillette et al. } \\
\text { 2002) }\end{array}$ \\
\hline 23 & & & Restore (ANL 2011) \\
\hline 24 & & & $\begin{array}{l}\text { A framework for reliability/availability assessment (Cadini et al. } \\
\text { 2017) }\end{array}$ \\
\hline 25 & \multirow{6}{*}{$\begin{array}{l}\text { Other } \\
\text { Approaches }\end{array}$} & Actor-Based Modeling & $\begin{array}{l}\text { Interdependent Energy Infrastructure Simulation System (IEISS) } \\
\text { (Toole and McCown 2008) }\end{array}$ \\
\hline 26 & & Empirical Modeling & $\begin{array}{l}\text { Framework for Electricity Production Vulnerability Assessment (Shih } \\
\text { et al. 2009) }\end{array}$ \\
\hline 27 & & System Dynamics Modeling & CIPMA Program (Pederson et al. 2006) \\
\hline 28 & & Physical Modeling & Petroleum Fuels Network Analysis Model (Pederson et al. 2006) \\
\hline 29 & & $\begin{array}{l}\text { Integrated Simulation } \\
\text { Platform }\end{array}$ & Critical energy infrastructures (Erdener et al. 2014) \\
\hline 30 & & $\begin{array}{l}\text { Integrated Simulation } \\
\text { Platform }\end{array}$ & Fast Analysis Infrastructure Tool (Pederson et al. 2006) \\
\hline
\end{tabular}




\subsubsection{Optimal Operation Modeling}

2 Optimal operation modeling is one of the most widely used method in the research area of energy

3 infrastructure resilience. In this method, when the system is interrupted, achieving resilience can

4 be interpreted as an optimization problem to restore the system within a short time while 5 minimizing the load shedding ratio.

Arif et al. (2018) solved the outage management problem by co-optimizing the repair, reconfiguration, and DG dispatch to maximize the picked-up loads and minimize the repair time considering reconfiguration and repair crew scheduling. Chen et al. (2016) and Ding et al. (2017) proposed a microgrid formation mechanism to restore critical loads after major faults at the grid caused by natural disasters. In this scheme, a mixed-integer linear program was formulated to maximize the total prioritized loads restored while satisfying self-adequacy and operation constraints of each microgrid. Similarly, Chen et al. (2018) formulated a mixed-integer linear program model for the sequential service restoration problem. This model can generate the optimal restoration sequences to coordinate dispatchable DGs and switchgears to energize the system on a step-by-step basis. Manshadi and Khodayar (2015) proposed a bi-level optimization methodology which took into consideration the interdependency between natural gas and electricity infrastructures. Through this model, the identification of most vulnerable components in the system, as well as the resilient generation and demand scheduling could be achieved. Yuan et al. (2016) proposed a model for resilient distribution system planning with hardening and DG based on two-stage optimization. In this model, a multi-stage and multi-zone-based uncertainty set was used to capture the uncertainty of natural disasters.

To sum up, existing optimal operation models share common object functions such as maximizing picked-up loads, minimizing repair time and economic investments. For restoration strategy development purpose, frequently considered measures include topology reconfiguration, DG dispatch, microgrid formulation, repair crew dispatch and switch device control. The problem is usually represented by mathematical models with equilibrium equations and certain constraints, including self-adequacy and operation constraints. An emerging number of researches focus on solving problems of demand scheduling and load flexibility in response to the adoption of building-to-grid, vehicle-to-grid technologies.

30 However, this type of model is usually focused on one single problem, either protection resource allocation or restoration, which are two separate stages of energy infrastructure resilience. On the other hand, the occurrence of the disaster is usually not simulated. If all these characteristics are coupled together, the optimization problem might get very complicated and the computational time problem will arise. Nezamoddini et al. (2017) compared the computational time of different scales of test systems. The computational time increases from 3 seconds to 4.2 hours when the system upgrades from IEEE 6-bus to IEEE 57-bus test system.

\subsubsection{Topological Network Modeling}

Power networks have been studied as a typical example of real-world complex networks (Chen et al. 2009). They can be modeled by extracting their topology. In this type of models, the power networks are represented by a set of vertices connected by a set of edges, where the vertices 
represent buses and the edges represent transmission lines. This type of model is typically applied in the structural vulnerability analysis of power networks.

Topological network models are easy to analyze due to their high level of abstraction and simplification. Buldyrev et al. (2010) used the topology of the interdependent power system and communication system to demonstrate the cascading fault evolving between the two systems. Page et al. (2013) proposed a simplified energy network modeling approach. Based on the topology of the original network, they used clusters that were aggregations of network nodes to build a less detailed model and calibrated it with detailed simulations. In this way, the number of variables was significantly reduced.

10 However, purely topological approaches fail to capture the physical properties and operational constraints of power systems and, therefore, can sometimes provide too optimistic analyses (Bompard et al. 2009). Hines et al. (2010) compared purely topological network models and higher fidelity models in the vulnerability modeling of electricity infrastructures. They used three measures of vulnerability: characteristic path lengths, connectivity loss, and blackout sizes. Their conclusion was that evaluating vulnerability in power networks using purely topological network models can be misleading. Chen et al. (2010) proposed a hybrid model for structural vulnerability analysis of power networks. Their approach embodied the traditional topological methodology and took into account important characteristics of power transmission networks such as the power flow distribution. Consequently, their hybrid model better approximated real power grids compared with a traditional topological network model.

Topology modification, or known as reconfiguration, plays an important role in the study of electric power system resilience, as a section can be reconnected to another power supply when an outage happens. Lin and Bie (2018) proposed a tri-level defender-attacker-defender model to harden the distribution system under malicious attacks. In this model, resilient operational measures such as topology reconfiguration and DG were simulated to study their impact on distribution system resilience.

\subsubsection{Agent-Based Modeling}

Agent-based models consist of dynamically interacting, rule-based agents (d'Inverno and Luck 2004; Wooldridge and Jennings 1995). A general definition of agent is: "an entity with a location, capabilities and memory. The entity location defines where it is in a physical space... What the entity can perform is defined by its capabilities... the experience history (for example, overuse or aging) and data defining the entity state represent the entity's memory." (Bonabeau 2002). An agent-based model can exhibit complex behavior patterns (Reynolds 1987) and provide valuable information about the dynamics of the simulated real-world system (Bonabeau 2002).

The application of ABM in the modeling and simulation of energy infrastructures mainly focuses on the analysis of the interactions between interdependent systems. Casalicchio et al. (2010) used ABM to model a system composed of a power grid and a communication network with agents representing the entire infrastructure, its subsystems and the humans involved in the scenario. In this model, an agent is described by its attributes, the services it provides to other agents, and the services provided by other agents. Li et al. (2016) modeled the integrated energy system of electricity and natural gas system. A two-hierarchy smart agent model is built as the basis for the system reliability analysis. The lower hierarchy are the component smart agents which represent 
the power lines, transformers, and electricity loads while the higher hierarchy are the zone agents which form the system topology.

Another important application of ABM is to simulate the socio-economic activities, such as the electricity market and human activities within the energy infrastructure framework. Zhou et al. (2011) simulated an electricity market with demand response from commercial buildings. In this model, agents were used to model different participants of the market such as power generation companies, load-serving entities, commercial building aggregators, and an independent system operator. SynCity (Keirstead et al. 2010) is a tool developed by Imperial College London for integrated modeling of urban energy systems. This tool adopts agent-based micro-simulations to simulate the daily-activities of citizens of the city. Each citizen makes stochastic decisions based on the pre-defined rules and according to the environment around him/her. Solanki et al. (Solanki et al. 2010; Solanki et al. 2007) used agents to model different operators in restoring the electric system.

14 The ABM technique has proved its advantages in the following aspects: 1) It can capture complicated interdependencies by simulating physical or economic flows among different infrastructures. 2) It enables the study of large-scale problems by avoiding complicated theoretical analysis. 3) It allows behavior analysis of customers or decision-makers by making certain rules. However, ABM still has limitations in that it is difficult to validate, and not all types of interdependencies can be included in one single model. Most existing agent-based models can only simulate one type of interdependencies such as the physical or logical interdependency (Zhang and Peeta 2011).

\subsubsection{Probabilistic Modeling}

In energy infrastructure resilience modeling, probabilistic algorithm is necessarily applied to capture the uncertain characteristics of the system failure. Many models adopt sequential Monte Carlo simulation method (Panteli and Mancarella 2017; Farzin et al. 2017; Cadini et al. 2017). A Monte Carlo simulation uses repeated sampling to determine the properties of some phenomenon or behavior (Fishman 2013). The essential idea is to use randomness solving problems that might be deterministic in principle. It is useful for gathering information about random objects, estimating certain numerical quantities, and optimizing complicated objective functions (Kroese et al. 2014).

31 Monte Carlo simulation in the field of energy infrastructure modeling is often employed for the simulation of weather events due to their high stochasticity. Panteli and Mancarella (2017) developed a time-series simulation model based on sequential Monte Carlo method to assess the impact of weather events on power-system resilience. With the knowledge of the hurricane occurrence frequency and its impact on power system components, Li et al. (2014) developed an algorithm to evaluate the risks of the power system in face of hurricanes. This method can be expanded to systems under other stochastic natural disasters. Similarly, Cadini et al. (2017) used a sequential Monte Carlo simulation scheme to simulate historical failures caused by both normal and extreme weather events. The simulation results were then used to evaluate the reliability of the studied power transmission system.

Another common application of Monte Carlo simulation in energy infrastructure modeling is to simulate the restoration process of disrupted infrastructures. For example, the software tool Critical Infrastructures Interdependencies Integrator (Gillette et al. 2002) developed by ANL used Monte 
Carlo simulation to estimate the time and cost required to restore a given infrastructure component, a specific infrastructure system, or a set of interdependent infrastructures.

It should be noted that Monte Carlo simulation can be integrated into other modeling frameworks, such as optimization-based models, to simulate the performance of energy systems. For example, Farzin et al. (2017) evaluated the role of outage management with Monte Carlo simulation, while considering the optimal power flow problem of the electric distribution system.

\subsubsection{Other Modeling Approaches}

Actor-based modeling: Similar to an agent-based model, an actor-based model is composed of actors that can make local decisions, create more actors, send messages and determine how to respond to messages received. The Interdependent Energy Infrastructure Simulation System (IEISS) (Toole and McCown 2008) developed by LANL is an actor-based infrastructure modeling, simulation, and analysis tool designed to understand interdependent energy infrastructures. The actors can realistically simulate the dynamic interactions within each of the infrastructures, with a specialization in simulating the interdependent electric power and natural gas infrastructures.

Empirical modeling: Empirical models are built based on historical data or expert experience. Shih et al. (2009) adopted data warehousing technique to conduct vulnerability assessment of interdependencies between coal mines, rail transportation, and electric power plants. A data warehouse is a system used for reporting and data analysis. It has the capability of bringing various datasets together and managing historical data. In this case, the data warehouse allowed an interactive analysis of historical and multi-dimensional data of varied granularities.

System dynamics modeling: System dynamics is a method for studying the behavior and the underlying structure of a complex system over time (Kirkwood 1998). It is widely used in the analysis of CI interdependencies. For example, the CIPMA program (Scott 2005) in Australia adopts the system dynamics model to examine the relationships and dependencies within and between CI systems, and to demonstrate how a failure in one sector can greatly affect the operations of other CI sectors.

Physical modeling: Petroleum Fuels Network Analysis Model (PFNAM) (Pederson et al. 2006) is a physical model developed by ANL to perform hydraulic calculations of pipeline transport of crude oil and petroleum products. Main outputs of the model include pressure and pipeline capacity estimates along the pipeline.

Integrated simulation platform: Some models are implemented in a way that several approaches are adopted for component models and then coupled together. Erdener et al. (2014) proposed an integrated simulation model for electricity and gas systems. The electricity and gas systems are first modeled separately and then linked by an (MATLAB-based) interface. The Fast Analysis Infrastructure Tool (FAIT) developed by SNL (Pederson et al. 2006) consists of a dependency model and an economic model. The dependency model is an object-oriented expert system model of infrastructure interdependencies. The economic model utilizes the input-output method for estimating the economic consequences of the disruption of an asset. An input-output model is a quantitative economic technique that represents the interdependencies between different branches of a national economy or regional economies (Ten Raa 2010). This economics-based method has been applied on CIs to capture the cascading economic effects of a disruption across different sectors (Zhang and Peeta 2011). 


\section{Proposed Resilience Indicators and Other Features}

\subsection{Resilience Indicators}

To address energy infrastructure resilience, a model should take into account certain dimensions of resilience. Sharifi (2016) proposed a framework for the analysis of community resilience assessment (CRA) tools. Within this framework, six criteria were proposed to evaluate the selected CRA tools. These include comprehensiveness in addressing multiple dimensions of community resilience, considering connections between different spatial scales, ability to measure changes across temporal scales, developing suitable measures for capturing uncertainties, collaboration with stakeholders, and leading to action plans. Cutter et al. (2014) measured the inherent resilience of counties in the United States according to six capitals identified in the extant literature: social, economic, housing and infrastructure, institutional, community, and environmental. Hosseini et al. (2016) identified four domains of resilience: organizational, social, economic, engineering.

Although different researchers may emphasize various aspects when assessing resilience, they do share some common grounds. Based on literature review, this paper proposes five indicators for energy infrastructure models from the resilience perspective. A model that successfully helps enhance energy infrastructure resilience should: be dedicated to certain stakeholders, intervene in one or more resilient infrastructure development phases, be able to simulate a certain stressor and the failure it caused, address interdependencies within or between infrastructure sectors, and integrate socio-economic characteristics.

Indicator 1 - Catering to different stakeholders: Urban infrastructures are owned and operated by different stakeholders who may not be aware of the interdependencies between their own infrastructure system and other systems (Hasan and Foliente 2015). Different stakeholders tend to have different priorities and considerations, when making decisions related to infrastructure investment, protection, or restoration. Hence, it is necessary to identify the stakeholder of a selected model before diving into further details. A stakeholder-oriented lens helps better understand a model's values and limitations. Francis and Bekera (2014) included stakeholder engagement as a key component in the analysis framework of engineered and infrastructure systems. Hasan and Foliente (2015) classified stakeholders according to their scales and roles into: international union, federal/state/local government, advocacy organizations, donors/financial institutions, insurance, utility companies, business, and households, individuals and communities.

Indicator 2 - Intervening in development phases: This indicator evaluates in which phase of infrastructure development a model can be employed. Four phases are distinguished: design, operation, restoration, and adaptation. Compliance with this indicator is decided as follows. If the model helps designers recognize the most vulnerable components in an infrastructure system and enhance the infrastructure resilient design, then the model is dedicated to the design phase. If the model focuses on the modeling and simulation of CI operational status, then the model is dedicated to the operation phase. If the model simulates restoration processes and helps develop restoration strategies, then the model is dedicated to the restoration phase. If the model integrates resilience enhancement techniques and considers the long-term adaptation of CIs to certain stressors, then the model is dedicated to the adaptation phase.

41 Indicator 3 - Dedicating to certain stressor and failure: In the research field of resilience, a 42 stressor represents the source that causes the system to change its original status. For CIs, there are 
generally two kinds of stressors: human-induced stressors such as terrorism and maloperations, and nature-induced stressors such as the climate change and extreme weather events. Identifying the stressor that a model is dealing with helps further evaluate the failure mode.

There are three types of infrastructure failures; namely, cascading failure, escalating failure, and common cause failure (Gillette et al. 2002; Sanghavi et al. 2017; Khosravi et al. 2017). The cascading failure refer to the disruption of one single infrastructure that is caused by a component failure, which is common in power grid disruptions. An escalating failure is a disruption in one infrastructure that exacerbates independent disruptions in other infrastructures. This kind of escalating effect is due to the complex interdependencies among infrastructure sectors and often leads to a longer time of restoration. A common cause failure is a disruption of two or more infrastructures at the same time resulted from a common cause. Existing models typically don't distinguish between "cascading failure" and "escalating failure", englobing them all under the concept of "cascading failure". In this paper, they are distinguished to investigate a models' temporal scale and the feature in simulating escalating effects of disasters. For example, a model for escalating failure not only simulates the immediate effects of a disruption, but also the propagated effects of a disaster among different sectors.

Indicator 4 - Taking into account different interdependencies: The interdependency between CIs is defined by Rinaldi et al. (2001) as "a bidirectional relationship between two infrastructures through which the state of each infrastructure influences or is correlated to the state of the other." Due to the complex relationships among different CI sectors, the vulnerability of CI systems is raised. The failure of one single component can lead to the failure of the entire system, even of the systems that rely on it. Some research results have proved the necessity to consider interdependencies between infrastructure systems when evaluating resilience and reliability (Li et al. 2016; Erdener et al. 2014).

There are four types of interdependencies: physical, cyber, geographic, and logical (Rinaldi et al. 2001). Physical interdependency expresses the physical reliance on material flow from one infrastructure to another. Typically, the output of one infrastructure may be the input of another infrastructure for operation. Cyber interdependency expresses the reliance on information transfer between infrastructures. An infrastructure has cyber interdependency if its state depends on information transmitted through the communication infrastructure. Geographic interdependency exists if a local environmental event can affect multiple infrastructures. That is, elements of multiple infrastructures are in close spatial proximity. Logical interdependency is a dependency that exists if two infrastructures depend on each other via a mechanism that fall into none of the above categories. It may be more closely linked to a control schema that links one infrastructure to another infrastructure without any direct physical, cyber, or geographic connection. Compliance with this indicator is confirmed if a model considers any of the four types of interdependencies inner the energy sector, or between energy and other sectors.

Indicator 5 - Involving socio-economic characteristics: Socio-economic characteristics are significant aspects of resilience. According to the City Resilience Framework (ARUP 2015), economy and society is one of the four basic elements of resilience, which is also recognized as the organizational resilience. The other three categories include the health and wellbeing of individuals, urban systems and services and, finally, leadership and strategy, which emphasize the role of people, place and knowledge in constructing a resilient city. When evaluating the resilience of energy infrastructures, a place-based perspective considering the people, as well as the socio- 
economics is more comprehensive. Many researchers point out that the socio-economic impacts resulting from the infrastructure disruptions can be very significant and needs serious considerations (Dore and Etkin 2000; Field et al. 2012)

This indicator examines if a selected energy infrastructure model considers the socio-economic impacts of the infrastructure failures or involves socio-economic activities in the simulation. Typical socio-economic characteristics include age, ethnic, religion, income, disaster insurance, and community resources.

\subsection{Other Modeling Features}

In order to further evaluate the models and gain insights into the characteristics of different modeling approaches in the context of energy infrastructure modeling, some more features of the models are discussed in this section; namely, data needs, model type, and time scale. Furthermore, whether the model is dynamic or static and whether the damage and restore processes are endogenous or exogenous are also discussed.

14 Data needs: The input data of a model usually include information about the layout of the simulated system, commodity flows, functioning, as well as numerical values for modeling parameters (Eusgeld et al. 2008). Data needs can vary largely according to the modeling approaches. A model with high data needs relies on high quality and large quantity of input data to provide reasonable outputs. On the contrary, a model with low data needs can provide plausible outputs, even when little data is accessible. This indicator analyzes the data needs of modeling approaches for energy infrastructures. For example, if a model requires databases as inputs, then the data demand level is high. If a model only has a few input variables, or only requires a small amount of profile data, then the data demand level is low. If the situation lies in between, then the demand level is regarded as medium.

However, it should be noted that there is a trade-off between a model's data need and its accuracy. High-fidelity models that reproduce the state and behavior of the real world better will rely more on high quantity and quality of data (Eusgeld et al. 2008). On the other hand, a model with lower data need might sacrifice its accuracy due to more assumptions. The data need of a model from a developer's angle is dependent on the development purpose. In the context of energy infrastructure resilience, for example, a model intended for impact analysis of weather events on the energy system will require more data than an optimization model that is developed for restoration strategy design. At last, a model's data need is also highly dependent on the data availability. Sometimes, developers have to make reasonable assumptions to compensate for the inaccessible data.

33 Model type: This indicator evaluates the computational mechanism of the models. Three types of models are distinguished: white box, black box, and grey box, which is their combination. In the white-box approach, the model uses governing laws of physics and the detailed knowledge of the underlying process (Afram and Janabi-Sharifi 2014). In the black-box approach, the system performance data is collected under normal use or under a specific test and a relationship is found between the input and output variables using mathematical methods (Owen and Kennedy 2009). In the grey-box approach, the model structure is formed using physics-based methods and the parameters are determined using estimation algorithms based on the measured data (Afram and

41 Janabi-Sharifi 2014). 
Time scale: The simulation time step and time horizon vary with the purpose and scenario of the energy infrastructure model. Holmgren (2006) simulated different hazard scenarios and gave their time scales. For major technical failure that disables a station in the sub-transmission or distribution grid, the corresponding vertices in the model are removed for 10 hours. For human factors and regular technical failures, the time scale is 1 to 2 hours. For snowstorm and lightning, the time scales are 8 hours and 0.5 hour, respectively. As for the repair time, it usually lasts hours depending on the damaged component in the system. Li et al. (2016) studied the reliability problem of integrated energy systems and gave the repair time of different components. Each kilometer of gas or heat pipeline will take 5 hours to repair. However, for gas-fired boiler, steam turbine, or absorption cooling plant, it will take 200 to 300 hours to repair. This indicator examines the time scale each model is designed to simulate over. Time step and time horizon are distinguished.

Dynamic or static: Dynamic models simulate the system performance in a time-dependent way, while static models calculate the system in equilibrium. Given the dynamic characteristics of energy infrastructure systems and the time-dependent instinct of resilience problems, most energy infrastructure resilience models are built dynamically. However, there do exist some static models. Manshadi and Khodayar (2015) simulated the resilient microgrid operation problem in a static way to identify the vulnerable components and the optimal operation plan considering the interdependency between power and gas systems. Nezamoddini et al. (2017) solved a resilient distribution network planning problem in equilibrium to coordinate the hardening and distributed generation resource allocation with the objective of minimizing the system damage. The physical model Petroleum Fuels Network Analysis Model (2006) conducts the hydraulic calculation of fuel pipelines in an equilibrant way.

Endogenous or exogenous damage/restore: The simulation of damage and restore processes are dealt with either endogenously or exogenously in resilience models. Models that don't obtain the disruption signal from outside but rather embed the disruptions inside the model are endogenous. Typically, the damage of the energy infrastructure is represented by the disconnection of lines, open switch devices, or randomly or intentionally removed nodes. Specially, in some agent-based models, different types of faults are propagated by agents. In exogenous models, the damage is generated by external random or non-random events, such as unit outages or system disruptions. Li et al. (2016) adopted Monte Carlo simulation to evaluate power system reliability by generating stochastic errors. The Fast Analysis Infrastructure Tool (FAIT) (2006) couples with other models to get the duration and magnitude of the disruption and recovery and conducts regional economic analysis.

\section{Discussions}

This section applies the above-proposed resilience indicators and other modeling features to evaluate the collected energy infrastructure models. The evaluation results can be found in Appendix 1 and 2. Findings regarding the resilience-related performance of the models and comparisons between different modeling approaches are discussed in the following text.

Stakeholder: Regarding "resilience for whom", Figure 1 shows the number of models with 
are the decision-makers, including the government. They serve the decision-makers during the infrastructure protection tasks, investment-related procedures, or when faced with infrastructure emergencies. The second most common stakeholders are infrastructure providers and operators, as over one third of the selected models were developed for their needs. Infrastructure providers and operators have significant impact on energy infrastructure resilience as they take charge of the operation and maintenance of infrastructures. Only two models include the consumers as relevant stakeholders. Although both decision-makers (especially the government), as well as providers and operators are in the service of consumers, surprisingly little attention has been paid to energy consumers when developing energy infrastructure models. Given that the ultimate goal of energy infrastructure resilience promotion is to better serve the consumers, it would be beneficial to consider their demands on energy supply and their response to energy infrastructure emergencies when seeking a holistic solution of energy resilience. Other stakeholders include research institutes, emergency responders, and engineers.

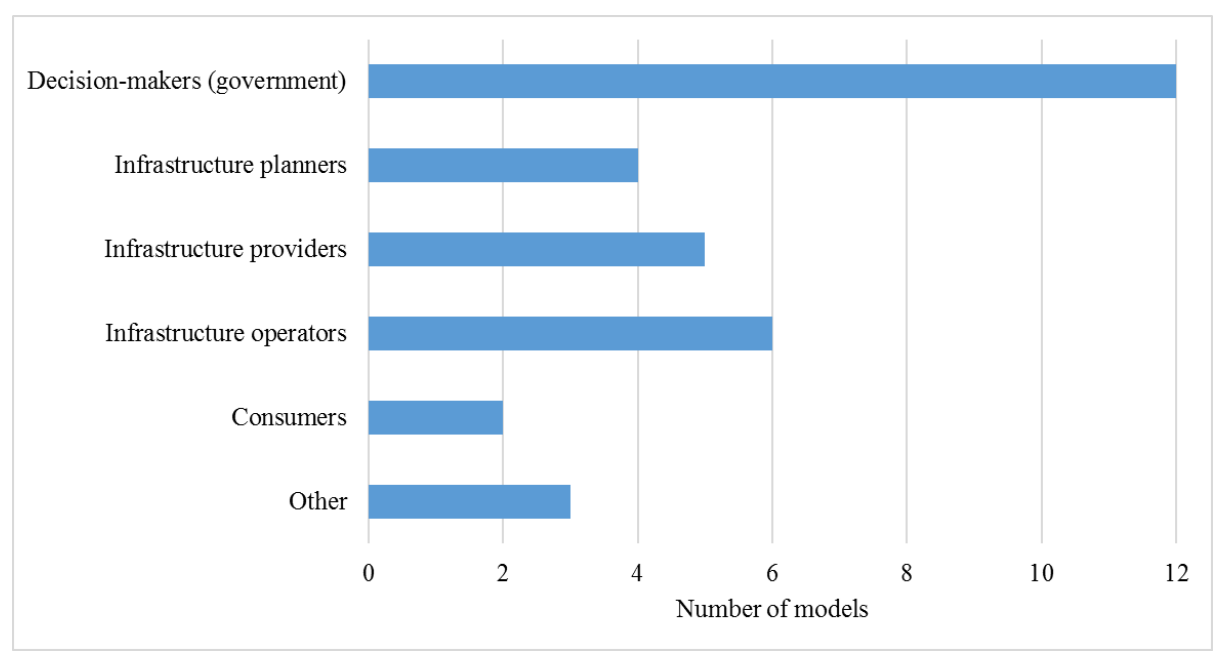

Figure 1 Number Distribution of Models with Different Stakeholders

Intervention phase: Regarding the infrastructure development phase in which a model is employed, most models in this study are found to be dedicated to the operation phase (Figure 2). Another 18 considerable proportion of models conduct restoration simulations of the energy infrastructures. 19 The least number of models take adaptational evolutions of energy infrastructures into account. 20 This distribution indicates that existing energy infrastructure models for resilience studies have been focusing on the operation phase. On the other hand, they are limited in integrating long-term adaptation strategies into the modeling framework, which should be an important dimension of 23 resilience enhancement. 


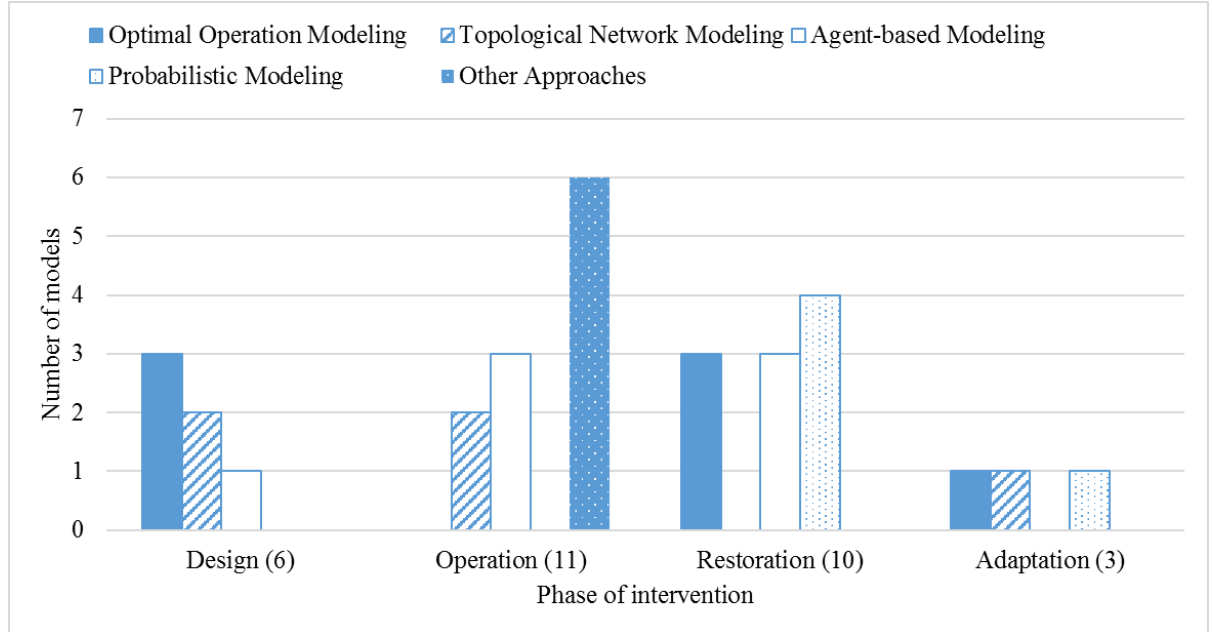

Figure 2 Number Distribution of Modeling Approaches Intervening in Different Phases

Stressor: Nearly $40 \%$ of the models simulating general disruptions of energy infrastructures. Instead of identifying a specific cause, these models focus on the failure of the infrastructure after the occurrence of a disaster and are generally applicable for disruption studies. $28 \%$ of the models are developed against intentional attacks while 19\% are against extreme weather events such as natural disasters. Only $3 \%$ of the selected models take economic disruptions as the stressor.

Failure: $40 \%$ of the models simulate cascading failures of energy infrastructures while $27 \%$ are for common cause failures, where several locations of disruptions occur together. However, only $16 \%$ of the models are able to simulate escalating failures of the critical infrastructures revealing that most existing energy infrastructure models don't account for the escalating effects of a failure. They tend to only focus on the immediate effects of a disruption. The varying temporal scale in the aftermath of disasters have been neglected by most selected models.

Interdependency: Regarding CI interdependencies, $43 \%$ of the selected models consider some types of interdependencies. The model "Critical energy infrastructures" (Erdener et al. 2014) studies the interdependency inner the energy sector between the natural gas and electric power system. Other models consider interdependencies between energy and other sectors such as transportation (Page et al. 2013; Gillette et al. 2002; ANL 2011; Shih et al. 2009; Keirstead et al. 2010) and telecommunication (Pederson et al. 2006; ANL 2011; Gillette et al. 2002). The rest of the models do not consider interdependencies but rather focus on the energy sector.

Socio-economic characteristics: $50 \%$ of the selected models involve socio-economic characteristics during the modeling and simulation process. However, most of these models only consider economic characteristics, such as economic impacts of infrastructure disruptions (Baker et al. 2003; Pederson et al. 2006) and investment optimization (Nezamoddini et al. 2017; Fang and Sansavini 2017; Page et al. 2013). Only four of all the selected models consider social impacts of a disaster, such as public hazards (Arif et al. 2018) or effects on population and housing (Bollinger 2011; Pederson et al. 2006; Keirstead et al. 2010).

Data needs: Figure 3 depicts the number distribution of modeling approaches with different data needs. Agent-based models tend to have the highest data needs, as $86 \%$ of them fall in medium and high data need columns. As for optimal operation models, topological network models and probabilistic models, most of them fall in the columns of low or medium data needs. This 
phenomenon is consistent with the characteristics of ABM, as historical data and attribute data will be needed to define each agent and certain interaction rules,

Model type: Concerning the model type, $93.3 \%$ of the selected models are white box. Only 3.3\% of them are grey box and 3.3\% are black box. In the grey box model (Panteli and Mancarella 2017), historical weather data are used to first determine the frequency distribution of certain weather events. The weather profile is then used as an input of the physics-based model. In the black box model (Shih et al. 2009), data warehousing and visualization techniques are used to manage nonspatial historical data which are then merged with geospatial data to model the potential impacts of a disruption to one or more mines, rail lines, or power plants.

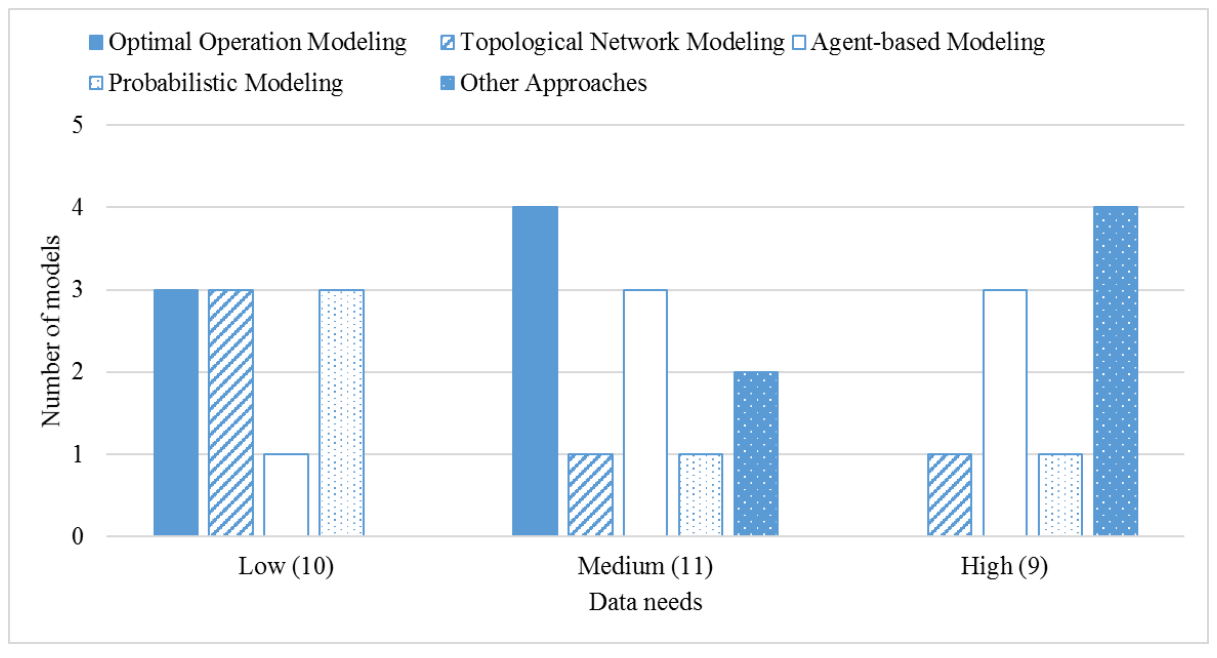

Figure 3 Number Distribution of Modeling Approaches with Different Data Needs

Other features: When looking at other features of the models, the time horizon varies from the short term of several hours to the long term of several years, depending on the problem tackled. Accordingly, the time step ranges from 1 minute or 1 hour to 1 week. Most models deal with energy infrastructure resilience problems dynamically. $63.3 \%$ of the models have endogenous damage or restoration while $16.7 \%$ have exogenous. For more details, the reader could refer to

17 Appendix 2.

\section{Conclusions}

19 Energy infrastructures are becoming more vulnerable due to the rising frequency of both natureand human-induced disasters. Hence, the resilience of energy infrastructures has gained much attention in recent years. This paper reviewed 30 energy infrastructure models from a resilience perspective. Through the review, research problems tackled by the models and typical modeling approaches adopted by researchers were summarized. Specifically, the authors proposed five resilience-based indicators to comprehensively address a model's capability in promoting energy infrastructure resilience. At last, other modeling features such as data needs and time scale were discussed to further evaluate the models.

The models collected in this work involve representative state-of-the-art energy infrastructure models implemented through various approaches. The addressed problems include optimal resource allocation and hardening planning, interdependency analysis, outage management and 
restoration, weather impact study, etc. The models intervene across planning, operation, restoration and adaptation phases of energy infrastructures. Based upon the review, the following observations are gained: The dominant stakeholder of the models are decision-makers, including government and regulators. Most selected models serve energy consumers indirectly as little attention is paid to energy consumers during the development stage. Most selected models focus on the operation and restoration phases of energy infrastructures. Long-term adaptation strategies are not integrated into the modeling framework by most models. Existent models tend to only consider immediate effects of system disruptions. The study on the propagated effects of the failure among different sectors is typically neglected. Although many selected models involve economic impact evaluation, only a few models take into account social parameters or consider social impacts of disasters. Concerning other modeling features, physics-based models are still the trend in energy infrastructure modeling, rather than data-driven techniques. Among others, agent-based models tend to have higher data needs than topological models and optimal operation models. The time horizon and time step vary significantly among the models, ranging from several hours to several years.

Based on the discussions above, future trends in the modeling and simulation of energy infrastructures are as follows:

Addressing larger temporal and spatial scale: As most existing energy infrastructure models focus on immediate effects of disruptions but are limited in capturing the dynamic behavior during longer terms, it remains to be explored how the models could be scaled over a larger temporal scale. Also, including the complex interactions across multiple CI sectors over different spatial scales helps making the model more realistic. However, the challenge of scalability lies in the computational time. How to employ more complexity in the model while reducing the computational time remains a challenge for future researchers.

Integrating more human and social aspects: Though existent models serve mostly the needs of decision-makers, energy consumers' behavior and potential in helping achieving energy infrastructure resilience would be more considered in the future. The emerging focus on humanin-loop control and demand response technologies also implies this trend. Also, since the impact of disasters eventually take place on the human and the society, it would be drawing more attention to integrate social characteristics in the modeling frameworks and study the social impacts of CI disruptions. However, the uncertainty in human behavior and the quantification of social factors remain a challenge.

33 Employing more smart resources and solutions: It was noticed from the review that smart technologies such as energy storage, demand response with flexible loads (e.g. electrical vehicles, flexible building loads) are integrated by some models to explore future possibilities of energy resilience. In the future, as these technologies develop and become more accepted, involving them in energy infrastructure models would be a trend.

38 Due to the limited number of models collected in this paper, there are certain limitations of the work: only four of the commonly used modeling approaches are deeply analyzed and the working scope is limited to the energy sector. In the future, the same evaluation methodology could be applied to transportation, water supply and sewer, communication and other CI sectors. 


\section{Acknowledgement}

2 This research was supported by the National Science Foundation under Award No. OAC-1638336. 3

4 Conflict of Interest

5 The authors declare that there's no conflict of interest that could affect the objectivity of this paper. 6 
References

Afram, A., and F. Janabi-Sharifi. 2014. Review of Modeling Methods for HVAC Systems. Applied Thermal Engineering, 67 (1-2):507-19.

Albasrawi, M. N., N. Jarus, K. A. Joshi, and S. S. Sarvestani. 2014. Analysis of Reliability and Resilience for Smart Grids. Proceedings of the 2014 IEEE 38th Annual Computer Software and Applications Conference, Vasteras, Sweden.

Amin, M. 2008. Challenges in Reliability, Security, Efficiency, and Resilience of Energy Infrastructure: Toward Smart Self-Healing Electric Power Grid. Proceedings of the 2008 IEEE Power and Energy Society General Meeting - Conversion and Delivery of Electrical Energy in the 21 st Century, Pittsburgh, USA.

ANL. 2017. "Restore: Modeling Interdependent Repair/Restoration Processes." Accessed on 09/15. http://www.anl.gov/sites/anl.gov/files/60362.pdf.

Arif, A., Z. Wang, J. Wang, and C. Chen. 2018. Power Distribution System Outage Management with Co-Optimization of Repairs, Reconfiguration, and DG Dispatch. IEEE Transactions on Smart Grid, 9 (5):4109-18.

ARUP. 2015. City Resilience Framework - the Rockerfeller Foundation. London, UK: ARUP Group.

Baker, G. H., S. Redwine, and J. Blandino. 2003. Network Security Risk Assessment Modeling Tools for Critical Infrastructure Assessment. Proceedings of the Critical Infrastructure Protection Project Workshop, Fairfax, USA.

Bie, Z., Y. Lin, G. Li, and F. Li. 2017. Battling the Extreme: A Study on the Power System Resilience. Proceedings of the IEEE, 105 (7):1253-66.

Bocchini, P., and D. Frangopol. 2012. Optimal Resilience- and Cost-Based Postdisaster Intervention Prioritization for Bridges Along a Highway Segment. Journal of Bridge Engineering, 17 (1):117-29.

Bocchini, P., D. M. Frangopol, T. Ummenhofer, and T. Zinke. 2013. Resilience and Sustainability of Civil Infrastructure: Toward a Unified Approach. Journal of Infrastructure Systems, 20 (2):04014004.

Bollinger, L. A. 2011. Evolving Climate-Resilient Energy Infrastructures. Delft, Netherlands: TU Delft.

Bompard, E., R. Napoli, and F. Xue. 2009. Analysis of Structural Vulnerabilities in Power Transmission Grids. International Journal of Critical Infrastructure Protection, 2 (1):5-12.

Bonabeau, E. 2002. Agent-Based Modeling: Methods and Techniques for Simulating Human Systems. Proceedings of the National Academy of Sciences, 99 (suppl 3):7280-7.

Buldyrev, S. V., R. Parshani, G. Paul, H. E. Stanley, and S. Havlin. 2010. Catastrophic Cascade of Failures in Interdependent Networks. Nature, 464 (7291):1025-8.

Cadini, F., G. L. Agliardi, and E. Zio. 2017. A Modeling and Simulation Framework for the Reliability/Availability Assessment of a Power Transmission Grid Subject to Cascading Failures under Extreme Weather Conditions. Applied Energy, 185:267-79.

Carlson, J., R. Haffenden, G. Bassett, W. Buehring, M. Collins III, S. Folga, F. Petit, J. Phillips, D. Verner, and R. Whitfield. 2012. Resilience: Theory and Application. Argonne, USA: Argonne National Lab.

Casalicchio, E., E. Galli, and S. Tucci. 2010. Agent-Based Modelling of Interdependent Critical Infrastructures. International Journal of System of Systems Engineering, 2 (1):60-75. 
Chen, B., C. Chen, J. Wang, and K. L. Butler-Purry. 2018. Sequential Service Restoration for Unbalanced Distribution Systems and Microgrids. IEEE Transactions on Power Systems, 33(2):1507-20.

Chen, C., J. Wang, F. Qiu, and D. Zhao. 2016. Resilient Distribution System by Microgrids Formation after Natural Disasters. IEEE Transactions on Smart Grid, 7 (2):958-66.

Chen, G., Z. Y. Dong, D. J. Hill, and G. H. Zhang. 2009. An Improved Model for Structural Vulnerability Analysis of Power Networks. Physica A: Statistical Mechanics and its Applications, 388 (19):4259-66.

Chen, G., Z. Y. Dong, D. J. Hill, G. H. Zhang, and K. Q. Hua. 2010. Attack Structural Vulnerability of Power Grids: A Hybrid Approach Based on Complex Networks. Physica A: Statistical Mechanics and its Applications, 389 (3):595-603.

Clark-Ginsberg, A. 2016. What's the Difference between Reliability and Resilience? Standford, USA: Standford University.

Cutter, S. L., K. D. Ash, and C. T. Emrich. 2014. The Geographies of Community Disaster Resilience. Global Environmental Change, 29:65-77.

d'Inverno, M., and M. Luck. 2004. Understanding Agent Systems. Berlin, Germany: Springer Science \& Business Media.

Dessavre, D. G., J. E. Ramirez-Marquez, and K. Barker. 2016. Multidimensional Approach to Complex System Resilience Analysis. Reliability Engineering \& System Safety, 149:34-43.

Dewit, A. 2016. Japan's 'National Resilience' and the Legacy of 3-11. The Asia-Pacific Journal, $14(6): 1-7$.

Ding, T., Y. Lin, G. Li, and Z. Bie. 2017. A New Model for Resilient Distribution Systems by Microgrids Formation. IEEE Transactions on Power Systems, 32 (5):4145-7.

Dore, M., and D. Etkin. 2000. The Importance of Measuring the Social Costs of Natural Disasters at a Time of Climate Change. Australian Journal of Emergency Management, 15 (3):46.

Dudenhoeffer, D. D., M. R. Permann, and M. Manic. 2006. CIMS: A Framework for Infrastructure Interdependency Modeling and Analysis. Proceedings of the 38th Conference on Winter Simulation, Monterey, Canada.

Erdener, B. C., K. A. Pambour, R. B. Lavin, and B. Dengiz. 2014. An Integrated Simulation Model for Analysing Electricity and Gas Systems. International Journal of Electrical Power \& Energy Systems, 61:410-20.

Eusgeld, I., D. Henzi, and W. Kröger. 2008. Comparative Evaluation of Modeling and Simulation Techniques for Interdependent Critical Infrastructures. Scientific Report, Laboratory for Safety Analysis, ETH Zurich:6-8.

Fang, Y., and G. Sansavini. 2017. Optimizing Power System Investments and Resilience against Attacks. Reliability Engineering \& System Safety, 159:161-73.

Farzin, H., M. Fotuhi-Firuzabad, and M. Moeini-Aghtaie. 2017. Role of Outage Management Strategy in Reliability Performance of Multi-Microgrid Distribution Systems. IEEE Transactions on Power Systems, 33 (3):2359-69.

Field, C. B., V. Barros, and T. F. Stocker. 2012. Managing the Risks of Extreme Events and Disasters to Advance Climate Change Adaptation: Special Report of the Intergovernmental Panel on Climate Change. Edited by Q. Dahe. Cambridge, England: Cambridge University Press.

Fishman, G. 2013. Monte Carlo: Concepts, Algorithms, and Applications. Berlin, Germany: Springer Science \& Business Media. 
Francis, R., and B. Bekera. 2014. A Metric and Frameworks for Resilience Analysis of Engineered and Infrastructure Systems. Reliability Engineering \& System Safety, 121:90-103.

Frangopol, D. M., and P. Bocchini. 2011. Resilience as Optimization Criterion for the Rehabilitation of Bridges Belonging to a Transportation Network Subject to Earthquake. Proceedings of the Structures Congress 2011, Las Vegas, USA.

Gillette, J., R. Fisher, J. Peerenboom, and R. Whitfield. 2002. Analyzing Water/Wastewater Infrastructure Interdependencies. Argonne, USA: Argonne National Lab.

Hasan, S., and G. Foliente. 2015. Modeling Infrastructure System Interdependencies and Socioeconomic Impacts of Failure in Extreme Events: Emerging R\&D Challenges. Natural Hazards, 78 (3):2143-68.

Hines, P., E. Cotilla-Sanchez, and S. Blumsack. 2010. Do Topological Models Provide Good Information About Electricity Infrastructure Vulnerability? Chaos: An Interdisciplinary Journal of Nonlinear Science, 20 (3):033122.

History.com. 2017. "9/11 Attacks." Accessed on 10/04. http://www.history.com/topics/9-11attacks.

History.com. 2018 "Hurricane Katrina." Accessed on https://www.history.com/topics/hurricane-katrina.

Holling, C. S. 1973. Resilience and Stability of Ecological Systems. Annual Review of Ecology and Systematics, 4 (1):1-23.

Holmgren, A. J. 2006. Using Graph Models to Analyze the Vulnerability of Electric Power Networks. Risk Analysis, 26 (4):955-69.

Hosseini, S., K. Barker, and J. E. Ramirez-Marquez. 2016. A Review of Definitions and Measures of System Resilience. Reliability Engineering \& System Safety, 145:47-61.

Huang, C.-N., J. J. Liou, and Y.-C. Chuang. 2014. A Method for Exploring the Interdependencies and Importance of Critical Infrastructures. Knowledge-Based Systems, 55:66-74.

Ji, C., Y. Wei, H. Mei, J. Calzada, M. Carey, S. Church, T. Hayes, et al. 2016. Large-Scale Data Analysis of Power Grid Resilience across Multiple US Service Regions. Nature Energy, 1 (5):16052.

Keirstead, J., N. Samsatli, and N. Shah. 2010. SynCity: An Integrated Tool Kit for Urban Energy Systems Modelling. Energy Efficient Cities: Assessment Tools and Benchmarking Practices:21-42.

Khosravi, F., M. Glaß, and J. Teich. 2017. Automatic Reliability Analysis in the Presence of Probabilistic Common Cause Failures. IEEE Transactions on Reliability, 66 (2):319-38.

Kirkwood, C. W. 1998. System Dynamics Methods. Tempe, USA: College of Business, Arizona State University.

Kroese, D. P., T. Brereton, T. Taimre, and Z. I. Botev. 2014. Why the Monte Carlo Method Is So Important Today. Wiley Interdisciplinary Reviews: Computational Statistics, 6 (6):386-92.

Li, G., Z. Bie, Y. Kou, J. Jiang, and M. Bettinelli. 2016. Reliability Evaluation of Integrated Energy Systems Based on Smart Agent Communication. Applied Energy, 167:397-406.

Li, G., P. Zhang, P. B. Luh, W. Li, Z. Bie, C. Serna, and Z. Zhao. 2014. Risk Analysis for Distribution Systems in the Northeast U.S. Under Wind Storms. IEEE Transactions on Power Systems, 29 (2):889-98.

Lin, Y., and Z. Bie. 2018. Tri-Level Optimal Hardening Plan for a Resilient Distribution System Considering Reconfiguration and DG Islanding. Applied Energy, 210:1266-79.

Manshadi, S. D., and M. E. Khodayar. 2015. Resilient Operation of Multiple Energy Carrier Microgrids. IEEE Transactions on Smart Grid, 6 (5):2283-92. 
McManus, S., E. Seville, D. Brunsden, and J. Vargo. 2007. Resilience Management: A Framework for Assessing and Improving the Resilience of Organisations. Christchurch, New Zealand: Resilient Organisations Research Programme.

Meerow, S., J. P. Newell, and M. Stults. 2016. Defining Urban Resilience: A Review. Landscape and Urban Planning, 147:38-49.

Moteff, J. D. 2010. Critical Infrastructures: Background, Policy and Implementation. Collingdale, USA: DIANE Publishing.

Nezamoddini, N., S. Mousavian, and M. Erol-Kantarci. 2017. A Risk Optimization Model for Enhanced Power Grid Resilience against Physical Attacks. Electric Power Systems Research, 143:329-38.

Ouyang, M. 2014. Review on Modeling and Simulation of Interdependent Critical Infrastructure Systems. Reliability Engineering \& System Safety, 121:43-60.

Owen, M. S., and H. E. Kennedy. 2009. ASHRAE Handbook: Fundamentals. SI ed. Atlanta, USA: ASHRAE.

Page, J., D. Basciotti, O. Pol, J. N. Fidalgo, M. Couto, R. Aron, A. Chiche, and L. Fournié. 2013. A Multi-Energy Modeling, Simulation and Optimization Environment for Urban Energy Infrastructure Planning. Proceedings of the 13th conference of international building performance simulation association, Chambéry, France.

Panteli, M., and P. Mancarella. 2017. Modeling and Evaluating the Resilience of Critical Electrical Power Infrastructure to Extreme Weather Events. IEEE Systems Journal, 11 (3):1733-42.

PCCIP. 1997. Critical Foundations: Protecting America's Infrastructures, The Report of the President's Commission on Critical Infrastructure Protection. Washington, DC, USA.

Pederson, P., D. Dudenhoeffer, S. Hartley, and M. Permann. 2006. Critical Infrastructure Interdependency Modeling: A Survey of US and International Research. Vol. 25. Idaho Falls, USA: Idaho National Lab.

Peter, H. L., L. Kristina Hamachi, H. E. Joseph, and L. S. James. 2015. Assessing Changes in the Reliability of the U.S. Electric Power System. Berkeley, USA: Lawrence Berkeley National Lab.

Reynolds, C. W. 1987. Flocks, Herds and Schools: A Distributed Behavioral Model. ACM SIGGRAPH computer graphics, 21 (4):25-34.

Rinaldi, S. M., J. P. Peerenboom, and T. K. Kelly. 2001. Identifying, Understanding, and Analyzing Critical Infrastructure Interdependencies. IEEE Control Systems, 21 (6):11-25.

Roege, P. E., Z. A. Collier, J. Mancillas, J. A. McDonagh, and I. Linkov. 2014. Metrics for Energy Resilience. Energy Policy, 72:249-56.

Sanghavi, M., S. Tadepalli, T. J. Boyle, M. Downey, and M. K. Nakayama. 2017. Efficient Algorithms for Analyzing Cascading Failures in a Markovian Dependability Model. IEEE Transactions on Reliability, 66 (2):258-80.

Scott, G. 2017. "Protecting the Nation." Accessed on 09/15. http://www.ga.gov.au/ausgeonews/ausgeonews200509/cip.jsp.

Sharifi, A. 2016. A Critical Review of Selected Tools for Assessing Community Resilience. Ecological Indicators, 69:629-47.

Shaw, R., and IEDM Team. 2009. Climate Disaster Resilience: Focus on Coastal Urban Cities in Asia. Asian Journal of Environment and Disaster Management, 1:101-16.

Shih, C. Y., C. D. Scown, L. Soibelman, H. S. Matthews, J. H. Garrett Jr, K. Dodrill, and S. McSurdy. 2009. Data Management for Geospatial Vulnerability Assessment of 

Interdependencies in US Power Generation. Journal of Infrastructure Systems, 15 (3):17989.

Solanki, J. M., S. Khushalani, and N. N. Schulz. 2007. A Multi-Agent Solution to Distribution Systems Restoration. IEEE Transactions on Power Systems, 22 (3):1026-34.

Solanki, J. M., S. K. Solanki, and N. Schulz. 2010. Multi-Agent-Based Reconfiguration for Restoration of Distribution Systems with Distributed Generators. Integrated ComputerAided Engineering, 17 (4):331-46.

Ten Raa, T. 2010. Input-Output Economics: Theory and Applications: Featuring Asian Economies. Singapore: World Scientific.

Toole, G. L., and A. W. McCown. 2008. Interdependent Energy Infrastructure Simulation System. In Wiley Handbook of Science and Technology for Homeland Security, edited by J. G. Voeller. New York, USA: John Wiley \& Sons.

Watson, J.-P., R. Guttromson, C. Silva-Monroy, R. Jeffers, K. Jones, and J. Ellison. 2014. Conceptual Framework for Developing Resilience Metrics for the Electricity, Oil, and Gas Sectors in the United States. Albuquerque, USA: Sandia National Lab.

Wooldridge, M., and N. R. Jennings. 1995. Intelligent Agents: Theory and Practice. The Knowledge Engineering Review, 10 (2):115-52.

Yuan, W., J. Wang, F. Qiu, C. Chen, C. Kang, and B. Zeng. 2016. Robust Optimization-Based Resilient Distribution Network Planning against Natural Disasters. IEEE Transactions on Smart Grid, 7 (6):2817-26.

Zhang, P., and S. Peeta. 2011. A Generalized Modeling Framework to Analyze Interdependencies among Infrastructure Systems. Transportation Research Part B: Methodological, 45 (3):553-79.

Zhou, Z., F. Zhao, and J. Wang. 2011. Agent-Based Electricity Market Simulation with Demand Response from Commercial Buildings. IEEE Transactions on Smart Grid, 2 (4):580-8. 


\section{Appendices}

2 Appendix 1: Proposed Resilience Indicators and the Evaluation Results of Selected Models

\begin{tabular}{|c|c|c|c|c|c|c|c|}
\hline & Modeling & I1 & I2 & I3 & & I4 & I5 \\
\hline & & Stakeholder & $\begin{array}{c}\text { Phase of } \\
\text { Intervention }\end{array}$ & Stressor & $\begin{array}{c}\text { Failure } \\
\text { Type }\end{array}$ & $\begin{array}{l}\text { Interdepe } \\
\text { ndencies }\end{array}$ & $\begin{array}{l}\text { Socio- } \\
\text { economic } \\
\text { Characte } \\
\text { ristics }\end{array}$ \\
\hline 1 & & N/A & Restoration & $\begin{array}{c}\text { General } \\
\text { disruptions }\end{array}$ & $\begin{array}{l}\text { Common } \\
\text { cause } \\
\text { failure }\end{array}$ & None & Yes \\
\hline 2 & & N/A & Restoration & $\begin{array}{c}\text { Extreme weather } \\
\text { events }\end{array}$ & $\begin{array}{l}\text { Common } \\
\text { cause } \\
\text { failure }\end{array}$ & None & None \\
\hline 3 & & N/A & Restoration & $\begin{array}{c}\text { Storms and } \\
\text { cyber-physical } \\
\text { attacks }\end{array}$ & $\begin{array}{l}\text { Common } \\
\text { cause } \\
\text { failure }\end{array}$ & None & None \\
\hline 4 & $\begin{array}{l}\text { Optimal } \\
\text { Operation } \\
\text { Modeling }\end{array}$ & $\begin{array}{l}\text { Infrastructure } \\
\text { planners and } \\
\text { operators }\end{array}$ & Design & $\begin{array}{l}\text { Intentional } \\
\text { attacks }\end{array}$ & $\begin{array}{l}\text { Common } \\
\text { cause } \\
\text { failure }\end{array}$ & Yes & Yes \\
\hline 5 & & N/A & Design & $\begin{array}{c}\text { Extreme weather } \\
\text { events }\end{array}$ & $\begin{array}{l}\text { Common } \\
\text { cause } \\
\text { failure }\end{array}$ & None & Yes \\
\hline 6 & & $\begin{array}{l}\text { Government and } \\
\text { infrastructure } \\
\text { operators and } \\
\text { consumers }\end{array}$ & Adaptation & $\begin{array}{l}\text { Intentional } \\
\text { attacks }\end{array}$ & Cascading & None & Yes \\
\hline 7 & & $\begin{array}{c}\text { Infrastructure } \\
\text { planners }\end{array}$ & Adaptation & $\begin{array}{c}\text { Intentional } \\
\text { attacks }\end{array}$ & Cascading & None & Yes \\
\hline 8 & & N/A & Operation & $\begin{array}{c}\text { Random and } \\
\text { intentional } \\
\text { attacks }\end{array}$ & Cascading & None & None \\
\hline 9 & & $\begin{array}{l}\text { Infrastructure } \\
\text { planners }\end{array}$ & Design & None & None & Yes & Yes \\
\hline 10 & $\begin{array}{l}\text { Topological } \\
\text { Network }\end{array}$ & N/A & Operation & $\begin{array}{c}\text { General } \\
\text { disruption }\end{array}$ & Escalating & None & None \\
\hline 11 & lvodellng & N/A & Adaptation & $\begin{array}{l}\text { Intentional } \\
\text { attacks }\end{array}$ & Cascading & None & None \\
\hline 12 & & N/A & Design & $\begin{array}{l}\text { Intentional } \\
\text { attacks }\end{array}$ & $\begin{array}{l}\text { Common } \\
\text { cause } \\
\text { failure } \\
\end{array}$ & None & Yes \\
\hline 13 & & Policy makers & Restoration & Overload & Cascading & None & Yes \\
\hline 14 & & $\begin{array}{l}\text { Policy makers, } \\
\text { research institutes } \\
\text { and infrastructure } \\
\text { providers }\end{array}$ & Operation & $\begin{array}{l}\text { General } \\
\text { disruption }\end{array}$ & Cascading & None & Yes \\
\hline 15 & & $\begin{array}{l}\text { Infrastructure } \\
\text { providers and } \\
\text { consumers }\end{array}$ & Operation & $\begin{array}{c}\text { General } \\
\text { disruption }\end{array}$ & Cascading & None & None \\
\hline 16 & $\begin{array}{l}\text { Agent-Based } \\
\text { Modeling }\end{array}$ & Decision-makers & Operation & $\begin{array}{c}\text { General } \\
\text { disruption }\end{array}$ & Cascading & Yes & None \\
\hline 17 & & $\begin{array}{l}\text { Infrastructure } \\
\text { providers, } \\
\text { planners and } \\
\text { emergency } \\
\text { responders }\end{array}$ & Operation & None & None & Yes & None \\
\hline 18 & & NA & Restoration & $\begin{array}{l}\text { General } \\
\text { disruptions }\end{array}$ & Cascading & Yes & None \\
\hline
\end{tabular}




\begin{tabular}{|c|c|c|c|c|c|c|c|}
\hline & \multirow{3}{*}{$\begin{array}{l}\text { Modeling } \\
\text { Approach }\end{array}$} & I1 & I2 & \multicolumn{2}{|l|}{ I3 } & \multirow{2}{*}{$\begin{array}{c}\text { I4 } \\
\begin{array}{c}\text { Interdepe } \\
\text { ndencies }\end{array}\end{array}$} & \multirow{2}{*}{$\begin{array}{c}\text { I5 } \\
\text { Socio- } \\
\text { economic } \\
\text { Characte } \\
\text { ristics }\end{array}$} \\
\hline & & Stakeholder & $\begin{array}{c}\text { Phase of } \\
\text { Intervention }\end{array}$ & Stressor & $\begin{array}{c}\text { Failure } \\
\text { Type }\end{array}$ & & \\
\hline 19 & & $\begin{array}{l}\text { Policy makers } \\
\text { and engineers }\end{array}$ & Design & None & None & Yes & Yes \\
\hline 20 & \multirow{5}{*}{$\begin{array}{l}\text { Probabilistic } \\
\text { Modeling }\end{array}$} & $\begin{array}{c}\text { Electrical } \\
\text { utilities, system } \\
\text { operators, } \\
\text { regulators and } \\
\text { policy makers }\end{array}$ & Adaptation & $\begin{array}{c}\text { Extreme weather } \\
\text { events }\end{array}$ & $\begin{array}{l}\text { Common } \\
\text { Cause } \\
\text { failure }\end{array}$ & None & None \\
\hline 21 & & NA & Restoration & $\begin{array}{c}\text { General } \\
\text { disruptions }\end{array}$ & Cascading & None & None \\
\hline 22 & & $\begin{array}{l}\text { Infrastructure } \\
\text { providers }\end{array}$ & Restoration & $\begin{array}{c}\text { General } \\
\text { disruption }\end{array}$ & None & Yes & Yes \\
\hline 23 & & Government & Restoration & $\begin{array}{c}\text { General } \\
\text { disruption }\end{array}$ & None & Yes & Yes \\
\hline 24 & & $\begin{array}{c}\text { Infrastructure } \\
\text { operators }\end{array}$ & Restoration & $\begin{array}{c}\text { Extreme weather } \\
\text { events }\end{array}$ & Cascading & None & None \\
\hline 25 & \multirow{6}{*}{$\begin{array}{l}\text { Other Modeling } \\
\text { Approaches }\end{array}$} & $\begin{array}{c}\text { Government } \\
\text { internal analysts }\end{array}$ & Operation & $\begin{array}{c}\text { Terrorist attack or } \\
\text { natural disaster }\end{array}$ & Cascading & Yes & Yes \\
\hline 26 & & $\begin{array}{c}\text { Infrastructure } \\
\text { operators and } \\
\text { decision-makers }\end{array}$ & Operation & $\begin{array}{c}\text { General } \\
\text { disruption }\end{array}$ & Escalating & Yes & None \\
\hline 27 & & $\begin{array}{l}\text { Infrastructure } \\
\text { operators, } \\
\text { business and } \\
\text { government } \\
\text { decision-makers }\end{array}$ & Operation & Terrorist attack & Escalating & Yes & Yes \\
\hline 28 & & Government & Operation & $\begin{array}{l}\text { General } \\
\text { disruption }\end{array}$ & Escalating & None & None \\
\hline 29 & & N/A & Operation & $\begin{array}{l}\text { General } \\
\text { disruption }\end{array}$ & Escalating & Yes & None \\
\hline 30 & & $\begin{array}{c}\text { Government } \\
\text { internal analysts }\end{array}$ & Operation & $\begin{array}{l}\text { Economic } \\
\text { disruptions }\end{array}$ & $\begin{array}{l}\text { Common } \\
\text { cause } \\
\text { failure }\end{array}$ & Yes & Yes \\
\hline
\end{tabular}

1 a) Yes: addressed.

2 b) None: not addressed.

3 c) N/A: not enough information provided. 
Appendix 2: Other Modeling Features and the Evaluation Results of the Selected Models

\begin{tabular}{|c|c|c|c|c|c|c|c|}
\hline & $\begin{array}{l}\text { Modeling } \\
\text { Approach }\end{array}$ & $\begin{array}{c}\text { Data } \\
\text { Needs }\end{array}$ & Model Type & Output Format & Time Scale & $\begin{array}{c}\text { Dynamic or } \\
\text { Static }\end{array}$ & $\begin{array}{c}\text { Endogenous } \\
\text { or } \\
\text { Exogenous } \\
\text { Damage/Re } \\
\text { store } \\
\end{array}$ \\
\hline 1 & \multirow{7}{*}{$\begin{array}{l}\text { Optimal } \\
\text { Operation } \\
\text { Modeling }\end{array}$} & Medium & White box & Data charts & $\begin{array}{l}\text { Several-hour } \\
\text { time horizon }\end{array}$ & Dynamic & Endogenous \\
\hline 2 & & Low & White box & Plan & N/A & Dynamic & Endogenous \\
\hline 3 & & Medium & White box & Plan & N/A & Dynamic & Endogenous \\
\hline 4 & & Medium & White box & Plan & N/A & Static & Endogenous \\
\hline 5 & & Medium & White box & Data and plan & $\mathrm{N} / \mathrm{A}$ & Dynamic & Endogenous \\
\hline 6 & & Low & White box & Data and plan & N/A & Static & Endogenous \\
\hline 7 & & Low & White box & Plan & N/A & Static & Endogenous \\
\hline 8 & \multirow{5}{*}{$\begin{array}{l}\text { Topological } \\
\text { Network Modeling }\end{array}$} & Low & White box & Data charts & N/A & Dynamic & Endogenous \\
\hline 9 & & High & White box & $\begin{array}{l}\text { Potential costs and } \\
\mathrm{CO}^{2} \text { emission }\end{array}$ & N/A & Dynamic & N/A \\
\hline 10 & & Low & White box & Data charts & N/A & Dynamic & Endogenous \\
\hline 11 & & Low & White box & Data charts & $\begin{array}{l}\text { Several-hour } \\
\text { time horizon }\end{array}$ & Dynamic & Endogenous \\
\hline 12 & & Medium & White box & Plan & N/A & Static & Endogenous \\
\hline 13 & \multirow{7}{*}{$\begin{array}{l}\text { Agent-Based } \\
\text { Modeling }\end{array}$} & Medium & White box & Metrics & $\begin{array}{l}\text { 1-week time } \\
\text { step }\end{array}$ & Dynamic & N/A \\
\hline 14 & & Medium & White box & Economic impacts & $\begin{array}{l}\text { 1-hour time } \\
\text { step }\end{array}$ & Dynamic & Exogenous \\
\hline 15 & & Low & White box & GIS & N/A & Dynamic & Exogenous \\
\hline 16 & & High & White box & $\begin{array}{l}\text { 3D visualized } \\
\text { model }\end{array}$ & N/A & Dynamic & Endogenous \\
\hline 17 & & High & White box & Graphic models & N/A & Dynamic & Endogenous \\
\hline 18 & & Medium & White box & Data charts & $\begin{array}{l}\text { 1-minute or } \\
\text { 1-hour time } \\
\text { step }\end{array}$ & Dynamic & Exogenous \\
\hline 19 & & High & White box & Map & $\begin{array}{l}\text { 1-year time } \\
\text { horizon }\end{array}$ & Dynamic & N/A \\
\hline 20 & \multirow{5}{*}{$\begin{array}{l}\text { Probabilistic } \\
\text { Modeling }\end{array}$} & Low & Grey box & Index & $\begin{array}{l}\text { 10-hour to } \\
50 \text {-hour time } \\
\text { horizon }\end{array}$ & Dynamic & Endogenous \\
\hline 21 & & Medium & White box & Plan & $\begin{array}{l}\text { 1-hour time } \\
\text { step }\end{array}$ & Dynamic & Endogenous \\
\hline 22 & & Low & White box & Graphs and tables & N/A & Dynamic & Endogenous \\
\hline 23 & & Low & White box & Graphs & N/A & Dynamic & Endogenous \\
\hline 24 & & High & $\begin{array}{l}\text { White and grey } \\
\text { box* }\end{array}$ & Data charts & 1 year & Dynamic & Endogenous \\
\hline 25 & \multirow{4}{*}{$\begin{array}{l}\text { Other Modeling } \\
\text { Approaches }\end{array}$} & High & White box & Map & N/A & Dynamic & N/A \\
\hline 26 & & High & Black box & GIS & $\begin{array}{l}\text { Between 1- } \\
\text { month and } \\
\text { 5-year time } \\
\text { horizon } \\
\text { N/A }\end{array}$ & Dynamic & Endogenous \\
\hline 28 & & High & White box & Graphs and tables & N/A & Static & N/A \\
\hline 29 & & Medium & White box & Data charts & N/A & Dynamic & Exogenous \\
\hline
\end{tabular}




\begin{tabular}{|c|c|c|c|c|c|c|c|}
\hline & $\begin{array}{l}\text { Modeling } \\
\text { Approach }\end{array}$ & $\begin{array}{c}\text { Data } \\
\text { Needs }\end{array}$ & Model Type & Output Format & Time Scale & $\begin{array}{c}\text { Dynamic or } \\
\text { Static }\end{array}$ & $\begin{array}{c}\text { Endogenous } \\
\text { or } \\
\text { Exogenous } \\
\text { Damage/Re } \\
\text { store } \\
\end{array}$ \\
\hline 30 & & Medium & White box & Reports & $\begin{array}{c}\text { 1-week to } 1- \\
\text { month time } \\
\text { horizon }\end{array}$ & Dynamic & Exogenous \\
\hline
\end{tabular}

1 *: This model has two sub-models that adopt different modeling methods. The restoration model is white box and the 2 cascading failure model is grey box.

3 N/A: not enough information provided. 